in vivo $34: 3069-3091(2020)$

doi:10.21873/invivo.12141

Review

\title{
IGF Bioregulation System in Benign and Malignant Thyroid Nodular Disease: A Systematic Review
}

\author{
APOSTOLOS KARAGIANNIS ${ }^{1}$, EVA KASSI ${ }^{2}$, ANTONIOS CHATZIGEORGIOU ${ }^{1}$ and MICHAEL KOUTSILIERIS ${ }^{1}$ \\ ${ }^{1}$ Department of Physiology, Medical School, National \& Kapodistrian University of Athens, Athens, Greece; \\ ${ }^{2}$ Department of Biological Chemistry, Medical School, \\ National \& Kapodistrian University of Athens, Athens, Greece
}

\begin{abstract}
Background/Aim: The insulin-like growth factor bioregulation system is implicated in cancer biology. Herein, we aim to review the evidence on the expression of the insulin-like growth factor 1 and 2 (IGF1 and IGF2), their receptors (IGF-Rs) and IGF-binding proteins (IGFBPs) in thyroid tissue and their possible association with benign and malignant thyroid nodular diseases. Materials and Methods: We systematically reviewed Pubmed and Scopus databases up to May 2020. A total of 375 articles were retrieved and analyzed. Results: Among 375 articles, 45 were included in this systematic review study. IGF1 was investigated in 31 studies, IGF2 in 1, IGF1 receptor in 15 and IGF-binding proteins in 13 articles. IGF1 expression in humans was dependent on the number and compound of benign nodules as well as the method of measurement. In differentiated thyroid carcinoma, a positive correlation between IGFI and immunohistological stage was documented in some studies while in others only a positive trend was observed. IGF-IR and IGFBPs expression was higher in malignant rather than benign lesions. There was only a positive trend for increased IGF2 expression in malignancy, while IGFBPs were in most studies statistically increased in various cancer types compared to benign nodular disease. Conclusion: The present data demonstrate that in most studies there is statistically positive expression of IGF-1 and less of IGF-2 in thyroid cancer compared to normal thyroid tissue.
\end{abstract}

This article is freely accessible online.

Correspondence to: Michael Koutsilieris, Department of Physiology, Medical School, National \& Kapodistrian University of Athens, 75 Micras Asias, Goudi-Athens, 115 27, Greece. Tel: +30 2107462597, Fax: +30 2107462571, email: mkoutsil@med.uoa.gr

Key Words: Insulin-like growth factors, thyroid nodule, thyroid cancer.
Thyroid cancer is the most common endocrine neoplasia. Over the last decades its rate has developed rapidly because of the multiple, congregate environmental factors and the highly advanced radiology diagnostic tools that detect small size tumors, which would have otherwise remained undiagnosed. Thyroid cancer is classified in 4 main categories: i) the differentiated carcinoma (papillary and follicular thyroid carcinoma), ii) the poor differentiated, iii) the medullary carcinoma, which derives from parafollicular $\mathrm{C}$ cells of the thyroid and iv) the anaplastic carcinoma, which has the poorest prognosis (1). Nowadays, several common oncogenes, such as RAS, RET, BRAF and p53 have been involved in thyroid carcinogenesis; however, they are rarely used as a prognostic factor in everyday clinical practice. Of note, their frequency varies among different populations, reflecting the different genetic and environmental factors implicated in carcinogenesis (2).

Insulin-like growth factor 1 (IGF1) is mainly synthesized and secreted by the liver under the control of growth hormone $(\mathrm{GH})$ that is, in turn, produced and secreted by the anterior pituitary lobe. There are two main IGF molecules, namely IGF1 and IGF2. For the time being, it is known that the IGFs bind to the following receptors: i) IGF1 receptor (IGF-1R), ii) IGF2 receptor (IGF-2R), iii) insulin receptor (IR), and iv) the hybrid IGF-1R/insulin receptor $(1,2)$ IGF1 has higher affinity for the IGF1 receptor and lower for the IGF2 receptor, while IGF2 binds only to IGF2 receptor. IR and the hybrid receptor have lower binding affinity for IGF1 and IGF2, while the IGF1 receptor, a tyrosine kinase receptor, is considered the main receptor of the IGF complex. IGF1 receptor is found in bones, vascular smooth muscle, cartilage, and several organs, included prostate, thyroid, breast and uterus (3).

In the circulation, IGFs bind to IGF-Binding Proteins (IGFBPs). Until now there are seven well characterized IGFBPs (1-7). These proteins play a regulatory role for IGFs either by inhibiting the binding of IGFs to their receptors, 
thus decreasing their bioactivity, or by promoting the IGFs binding to the receptors, thus increasing their half time and activity. Among the increasing number of IGF binding proteins, a large group of novel RNA binding proteins, defined as IGF2BPs or IGF2 mRNA-binding proteins (IMPs), is also included (4).

IGF1 plays an important role in cancer and its action is involved in several functions related to carcinogenesis, such as cell proliferation, apoptosis, migration and neovascularization. In thyroid cancer, binding of IGF1/2 to IGF-1R triggers the RAS/RAF/MEK/ERK and $\mathrm{PI} 3 \mathrm{~K} / \mathrm{AKT} / \mathrm{mTOR}$ pathways that causes the inhibition of apoptosis and favors cell proliferation (5). In parallel, the activation of the above-mentioned pathways increases the function of $\mathrm{Na} / \mathrm{I}$ symporter (NIS) in primary tumor thyrocytes. Moreover, the high levels of these growth factors correlate positively with thyroid stimulation hormone (TSH) levels, which in turn exerts growth effects on thyroid. Finally, the IGF complex interacts with other tyrosine kinase receptors, such as the vascular endothelial growth factor receptor (VEGFR) and the epidermal growth factor receptor (EGFR), which participate in the mechanism of carcinogenesis, further increasing the complexity of the signaling pathways involved in the process (5).

The gene that encodes IGF consists of 6 exons and can develop multiple heterogeneous copies via an alternative splicing mechanism that takes place during the encoding process. Apart from IGFs, IGF-1Ec is an IGF1 transcript of 49 base pairs, which is part of exon 5 (6). This molecule also shows increased bioactivity in cancer and has been recently shown to be involved in the mechanism of carcinogenesis (6).

Herein, we aimed to systematically review the available evidence in bibliography in order to investigate the role of IGF system (IGF1/IGF2/IGF1 receptors/IGFBPs) in thyroid cancer as well as in benign thyroid nodular disease in humans.

\section{Materials and Methods}

Literature search. We systematically reviewed the literature in Pubmed and Scopus databases up to May 2020. Moreover, the bibliographies of all relevant articles were searched manually in order to retrieve additional studies. The following search terms were used without a year of publication threshold: ("IgF" OR "IgF1" OR "IgF2" OR "Insulin-like growth factor" OR "IGF Binding Protein" OR "IGF Receptor") AND ("thyroid cancer" OR "thyroid nodules" OR "thyroid goiter" OR "thyroid nodular disease"). Only articles in English were evaluated.

Study selection. Any original article presenting data on the existence of IGF1, IGF2, its receptors and binding proteins in patients with either benign nodules, goiter or thyroid cancer of any type, was evaluated. Studies conducted to experimental animals and cell lines were excluded. Case reports were also excluded.
Data extraction. The demographic data collected for each study included the author's name, the year of publication, the study design, the country of origin, the number of patients involved and the type of thyroid cancer they had. We also referred the studied molecule and its presence in either benign or malignant disease, the method of its measurement and any potential relationship with other factors, such as age, sex, tumor size and invasion to surrounding tissues.

\section{Results}

Our search revealed 375 articles, 146 articles from PubMed and 229 from Scopus. Additionally, 12 articles from the manual searching of article's bibliographies were retrieved. After applying the inclusion criteria (Figure 1), 45 studies were included in this review (7-51). Of those, 4 were prospective $(9,11,16,19), 10$ were retrospective $(8,10,14$, $15,17,22,25,40,42,44), 2$ were case-control studies $(20$, $24)$ and for the rest of the studies the design method was not referred.

There was a heterogeneity regarding the studied molecules among the several studies. IGF1 was investigated in 31 studies (7-25, 27-38) and IGF2 in one (26). The receptor of IGF1 was measured in 15 studies $(7,15,18,22,27,29,31$, $34,35,39-44)$ and its binding proteins in $13(11,13,20,24$, $35,36,45-51)$, while 3 articles studied the binding proteins of IGF2 $(46,48,49)$. Each molecule was measured using different assays: i) ELISA-like assays such as radioimmunoassay (RIA), immune radiometric assay (IRMA) and chemiluminescence were used in 16 studies (7, $9,11-13,16,17,21,24,28,31-33,36,38,39)$, ii) immunohistochemistry (IHC) in $22(8,10,14,15,18,19,22$, $25,27,29,30,34,35,37,40-42,44-46,48,49)$, iii) polymerase chain reaction (PCR) in $6(14,15,20,34,43$, $47)$, iv) reverse transcription polymerase chain reaction in 7 $(8,18,26,31,48,50,51)$, v) immunolight in one (23), vi) northern analysis in $3(29,33,36)$, vii) in situ hybridization in one (34), viii) western blot in $2(36,41)$ and ix) guanidium thiocyanate method in one (36). Eight of them referred only to benign thyroid diseases $(9,11,12,17,19,21,24,33)$, one to medullary thyroid carcinoma (MTC) (39), one to anaplastic thyroid carcinoma (ATC) (32), 7 to papillary thyroid carcinoma (PTC) $(15,23,30,40,41,43,44)$, and the rest to combinations of benign and malignant tumors. Nineteen studies performed correlation analyses between the studied molecule and factors, such as tumor size, sex, age, aggressiveness, capsular, muscular, vascular or lymph nodes invasion $(8-11,13,17,18-21,27,29,34,40,42-44,47,49)$.

IGF in benign thyroid diseases. The characteristics of the included studies are described in Table I. Regarding benign diseases, Du et al. have concluded that the serum IGF1 levels are significantly decreased in patients with nodules compared to the control group $(p<0.001)(9)$. Among patients with benign lesions, the incidence of nodule development 


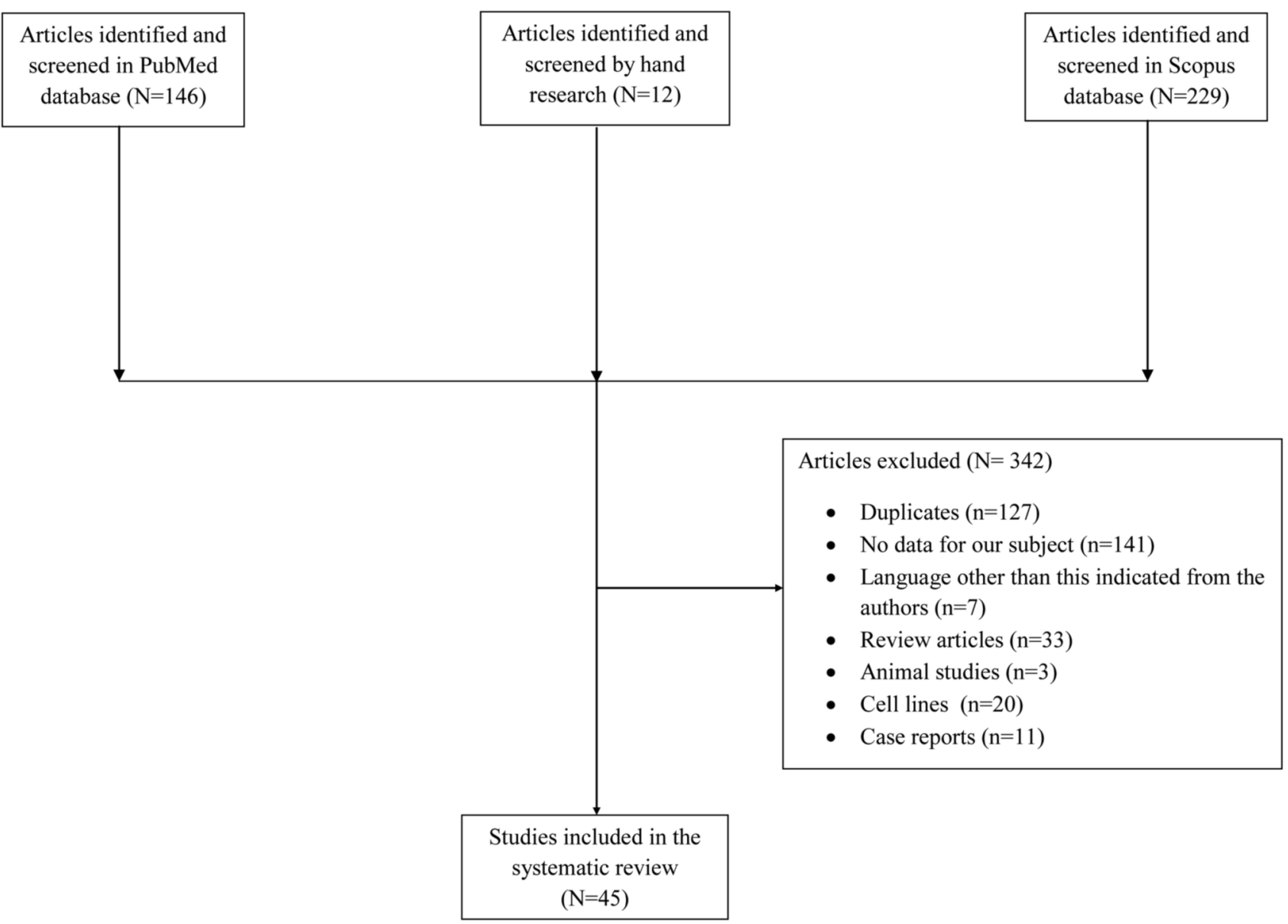

Figure 1. Flow diagram of the systematic search and study selection process.

was negatively correlated with the IGF1 levels; specifically, when divided into 4 groups with different IGF1 levels, namely: i) $\mathrm{Q} 1<83.34 \mathrm{ng} / 1$, ii) $\mathrm{Q} 2=83.35-120.01 \mathrm{ng} / 1$, iii) Q3=120.02-222.3 ng/l, and iv) Q4>222.31 ng/l, there was a significant difference in the number of nodules between groups Q1 and Q4. Additionally, IGF1 levels were positively correlated with 25-hydroxyvitamin D [25(OH)D3] levels $(\mathrm{r}=0.123, p=0.037)$ and negatively with fasting blood glucose $(\mathrm{r}=0.207, p<0.001)$. A study by Atlas et al. in 2017, measured prospectively the intranodular IGF1 levels using ELISA after ultrasound- (U/S) guided fine needle aspiration, as well as serum IGF1 levels in male and female patients with nodular goiter (11). They found that serum IGF1 levels were significantly higher than the intranodular ones $(p=0.001)$, and were also statistically higher in subjects with multinodular goiter compared to single nodules $(p=0.001)$. Regarding serum IGF1, there was no difference between the two groups. Serum IGF1 was significantly lower in males than females $(p=0.028)$, while there was no significant correlation with age or body mass index (BMI).
Another study in that same year compared patients with thyroid nodules with and without metabolic syndrome and patients without thyroid nodules and with metabolic syndrome. They found no significant correlation between IGF1 and the presence of thyroid nodules (12). Dogan et al., retrospectively analyzed with immunoradiometric assay (IRMA) the IGF1 levels in acromegalic patients with or without nodules (17). There was no significant difference between the two groups. Importantly, the post-treatment IGF1 levels were higher in patients with uncontrolled acromegaly compared to those with controlled disease $(p=0.001)$ and were positively correlated to thyroid volume $(\mathrm{r}=0.423, p=0.004)$. Basturk et al. have concluded that IGF1 is significantly higher in benign nodules than in extranodular healthy tissues and does not correlate with any feature, including hot or cold nodules (19).

Another study in patients with thyroid adenoma versus the control group, showed a statistically significant difference in IGF1 levels between benign lesions and healthy tissue (21). Higher IGF1 levels were also found in patients with solid 


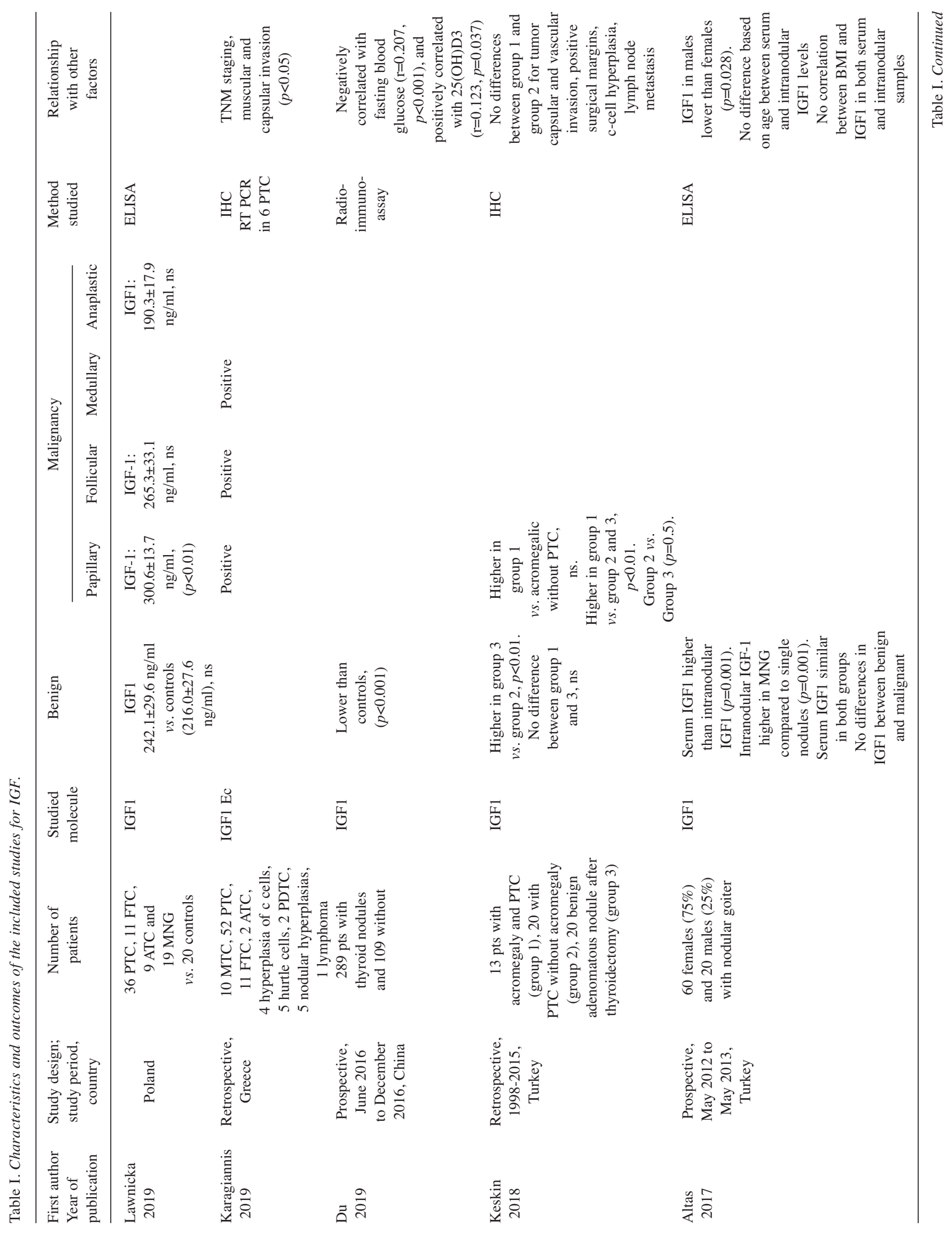




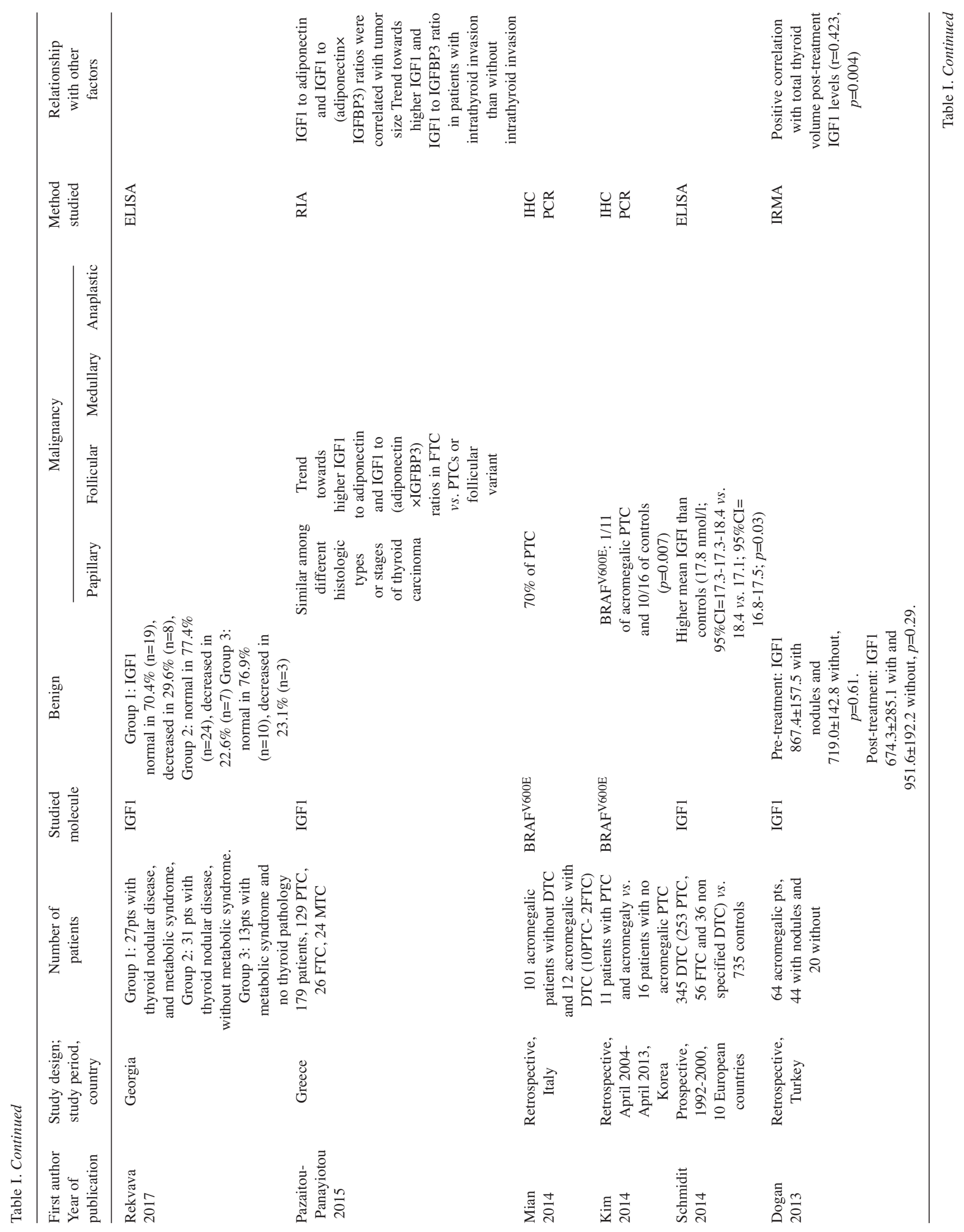




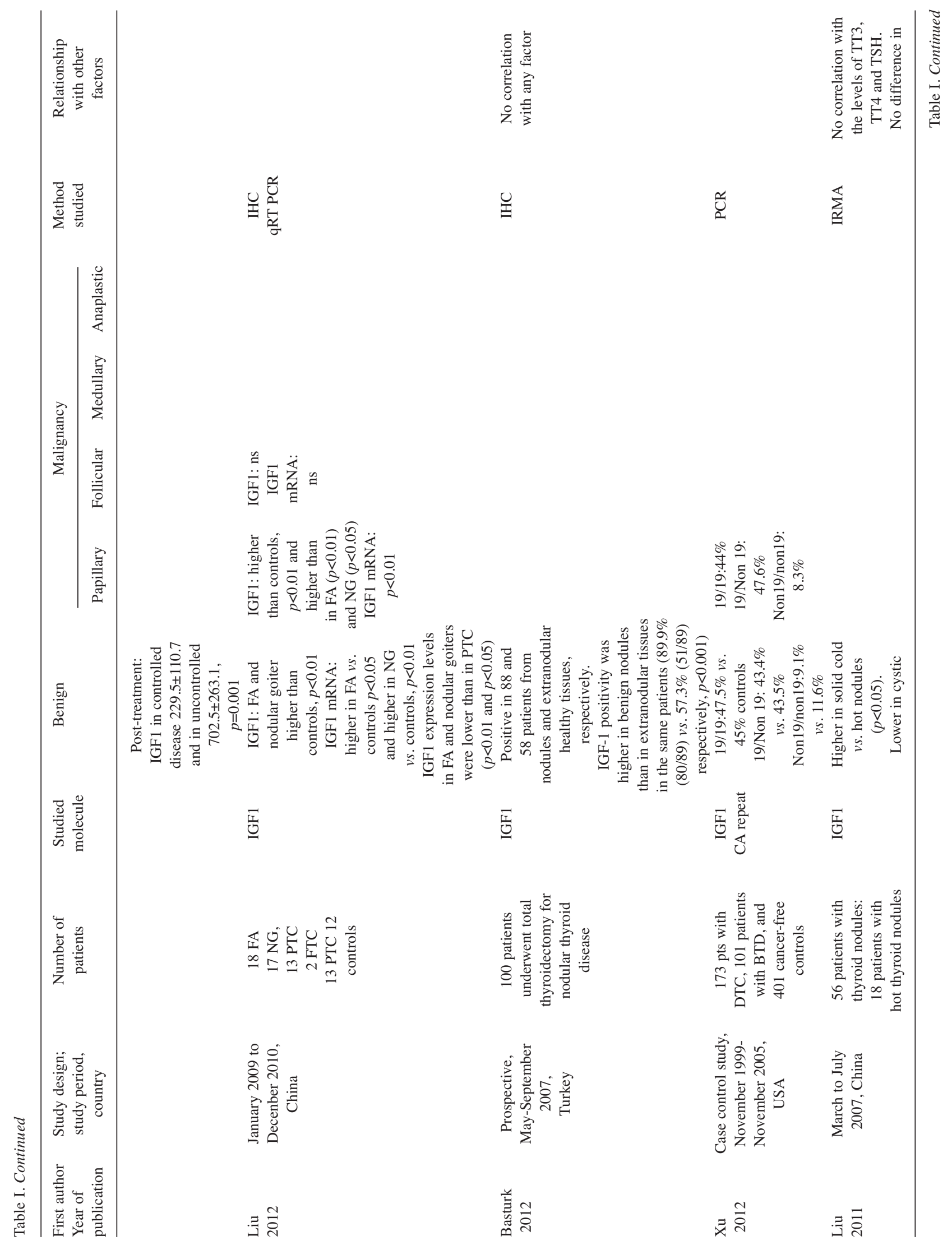




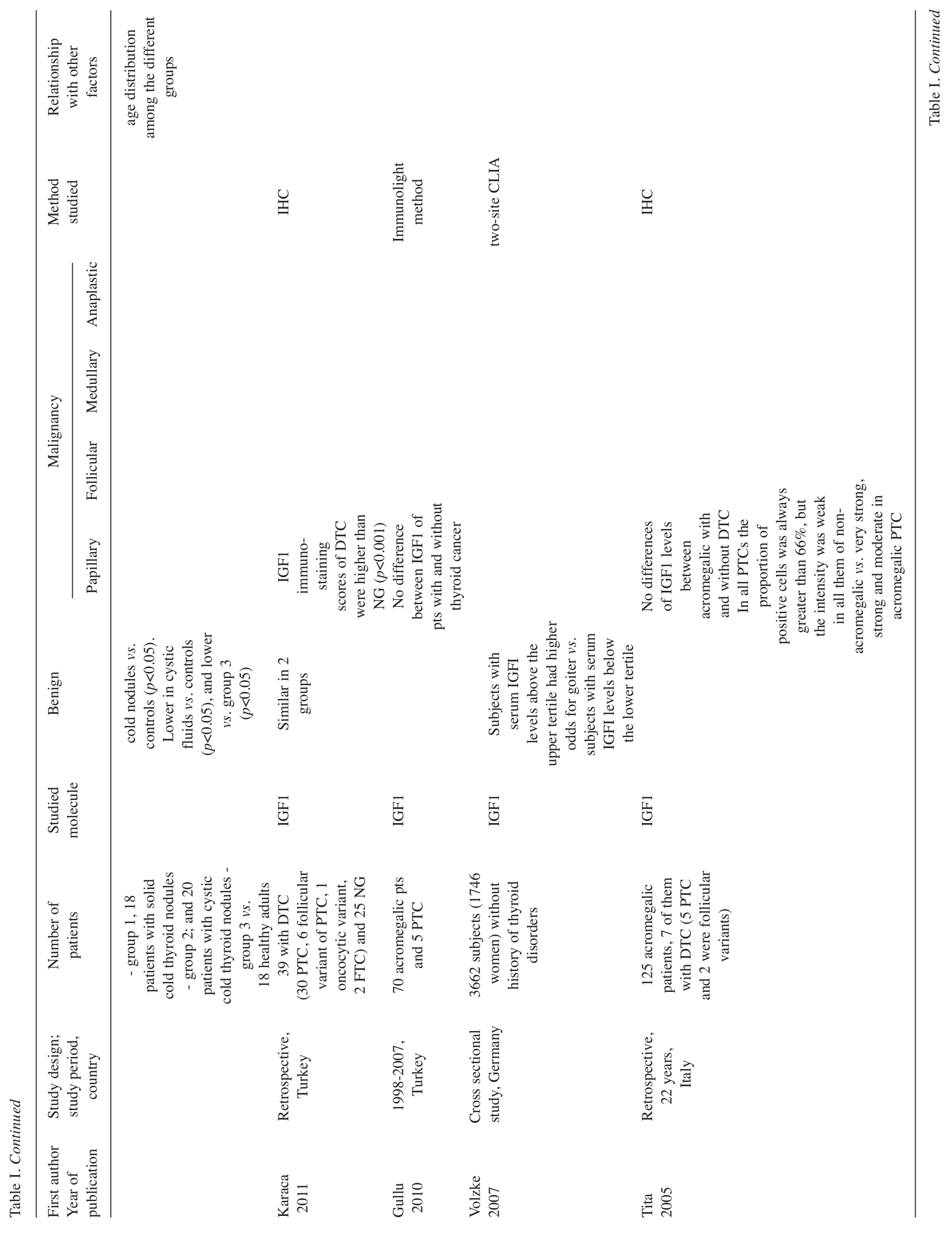




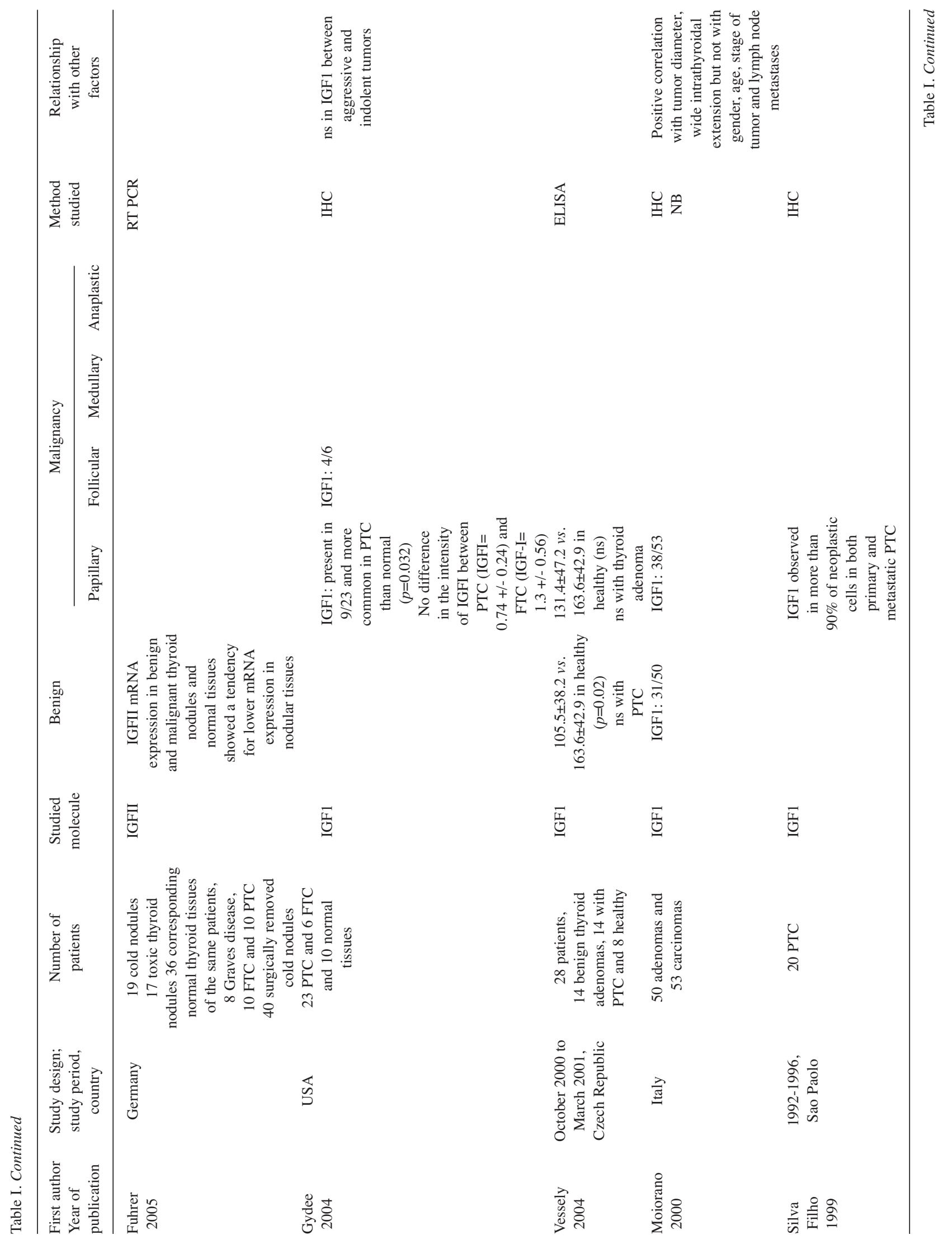




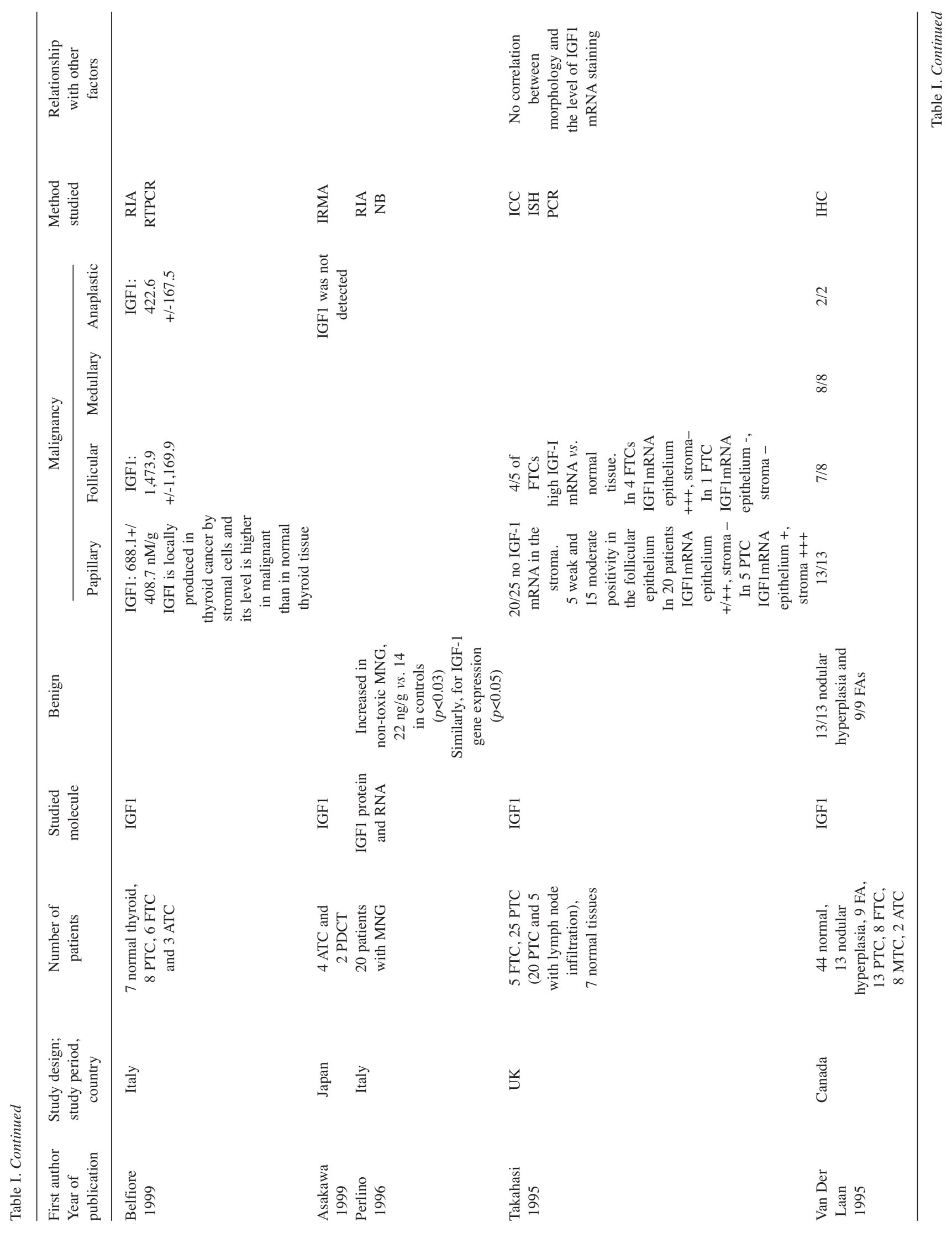




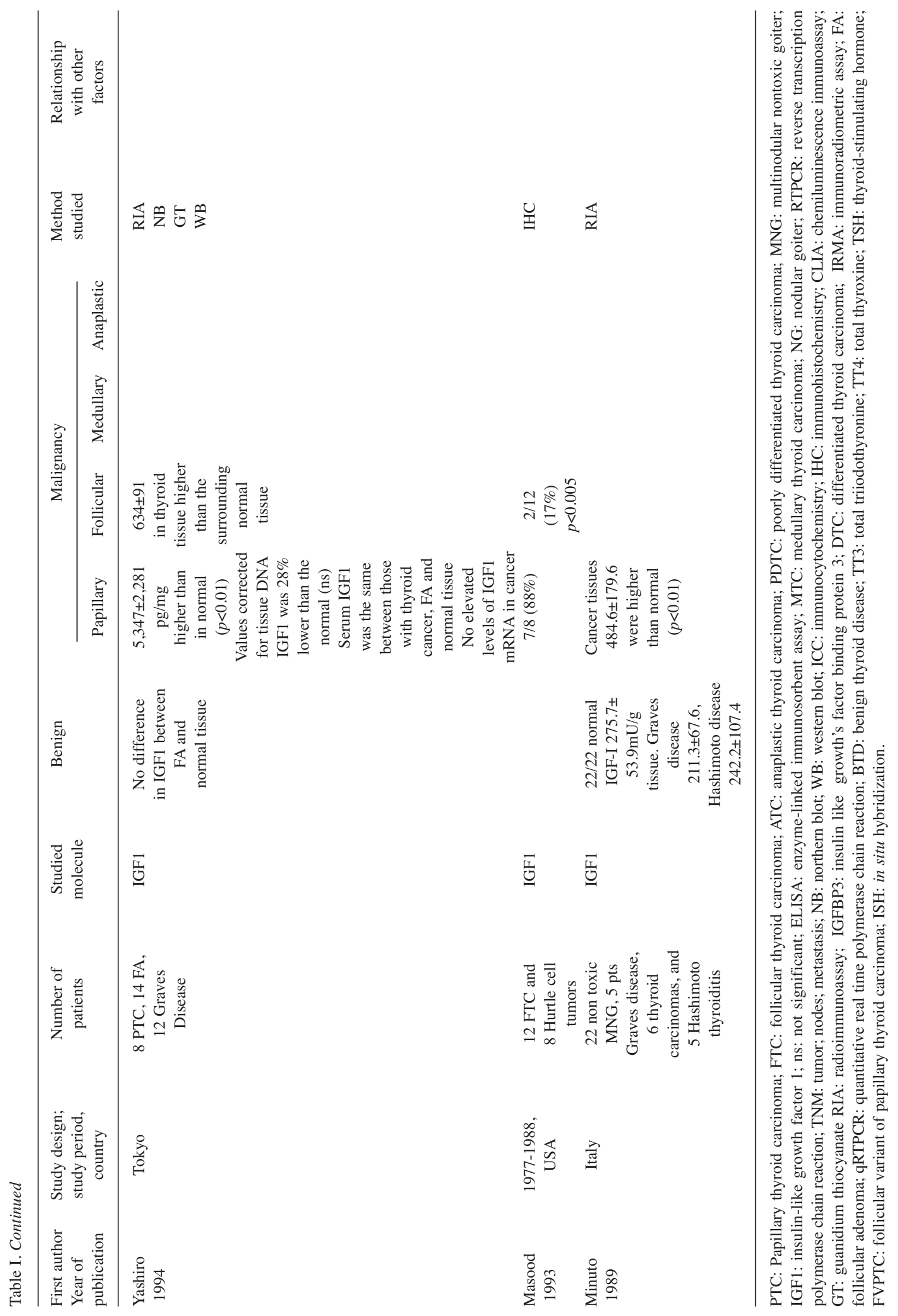


cold nodules compared to hot ones $(p<0.05)$. Regarding patients with cystic cold nodules, IGF1 levels in serum and cystic fluids were significantly lower than in normal thyroid tissue $(p<0.05)$. Another study conducted on subjects without a history of thyroid disorders, showed that those with IGF1 levels above the upper tertile had higher odds for goiter development compared to those with IGF1 levels below the lower tertile (24). Finally, a study of 20 patients found that both IGF1 mRNA and protein levels were statistically higher in those with multinodular disease compared to controls (33).

IGF in malignant thyroid diseases. The characteristics of the included studies are described in Table I. In the first study, Lawnicka et al., measured serum IGF1 levels in i) 36 subjects with PTC, ii) 11 with FTC, iii) 9 with ATC and iv) 19 with multinodular nontoxic goiter (7). When compared to 20 controls, IGF1 was significantly higher in PTC patients (300.6+-13.7 vs. 216+-27.6, $p<0.01)$, but no significant difference regarding the other groups. In a study by Karagiannis et al., IHC analysis of IGF1-Ec has shown that it is expressed in PTC, FTC and MTC, while in differentiated cancer it correlates with TNM staging, as well as muscular and capsular invasion $(p<0.05)(8)$. PCR was assessed only in 6 PTC samples and was positive in more aggressive cancers. Keskin et al., have compared patients with i) PTC and acromegaly, ii) PTC only and iii) others with adenomatous nodules; and have found serum IGF1 levels in acromegalic subjects with PTC to be statistically higher compared to patients with PTC only or benign nodules (10). Nevertheless, no correlation was found with any other factor in this study. In a study including 179 patients with PTC, FTC and MTC, serum IGF1 levels were similar among different histological types or stage of disease and there was a trend towards higher levels of the IGF1 to adiponectin ratio and IGF1 to "adiponectin X IGFBP3" ratio in FTCs compared to PTCs (13). These markers were correlated with tumor size and marginally with intrathyroid invasion.and introduced by the authors since IGF- 1 showed a positive and adiponectin a negative correlation with thyroid cancer.

A multicenter study including 345 patients with differentiated thyroid carcinoma versus 735 controls, demonstrated a higher mean serum IGF1 concentration in patients as compared to controls $(p=0.03)$ (16). Similarly, in a small cohort study, patients with follicular adenoma and nodular goiter had higher levels of serum IGF1 than controls $(p<0.01)$ and those with PTC had higher levels compared to those with the benign diseases measured by IHC and PCR ( $p<0.01$ and $p<0.05$, respectively for each method) (18). Xu et al., studied a CA repeat polymorphism in the promoter region of the IGF1 gene and more specifically the homozygous genotype 19/19. In this case-control study they found no significant association regarding IGF1 levels in patients with DTC, benign thyroid disease (BTD) and healthy controls (20). Karaca et al. have compared two groups, those with DTC and those with nodular goiter; they found similar levels of serum IGF1 in the two groups, but the immunostaining scores of those with DTC were statistically higher $(p<0.001)$ compared to nodular goiter (22). Furthermore, Tita et al., have studied 7 acromegalic patients with DTC, and have found similar IGF1 levels in patients with and without DTC (25). Moreover, Gydee et al., comparing patients with PTC, FTC and normal controls have found that the staining for IGF1 was more abundantly detected in PTC patients compared to controls but almost the same as in patients with FTC (27). In contrast, in another trial including individuals with PTC, benign nodule, as well as healthy subjects, the serum IGF1 levels were significantly lower $(p=0.02)$ in patients with thyroid adenoma compared to healthy controls (28). Additionally, IGF1 levels were higher in healthy subjects compared to those with PTC; albeit, not significantly.

Two studies have identified the mutation $\mathrm{BRAF}^{\mathrm{V} 600 \mathrm{E}}$. The first one compared paraffin-embedded surgical specimens of PTC patients with or without acromegaly and found that this mutation does not play an important role in carcinogenesis (15). In the other one the presence of that mutation was analyzed by direct sequencing in thyroid samples and showed that the DTC risk is associated with the aforementioned mutation and is not correlated with GH/IGF1 levels (14).

In a study with patients with adenomas and carcinomas, serum IGF1 was increased in both populations as compared to healthy individuals, while a positive correlation with tumor diameter and wide intrathyroidal extension was shown (29). Another trial investigated the expression of mRNA IGF1 in the epithelium and stroma of tumor cells and found that the epithelium of PTCs but not stroma cells expressed it, with the exception of 5 PTCs with lymphoid infiltrate, which were found to express more IGF1 in the stroma than in the epithelium (34). In FTCs, mRNA IGF1 expression was stronger in epithelial cells than in the stroma (34). Additional studies have also revealed a higher expression of IGF1 in thyroid malignancies compared to healthy controls $(30,31,35$, $37,38)$. In contrast, Yashiro et al. have found no increased IGF1 mRNA in cancer compared to normal thyroid tissues (36). A trial in which 4 anaplastic and 2 poorly differentiated thyroid carcinoma cell lines were investigated, showed that IGF1 protein levels were not detected in any cell line (32).

Finally, only one study has evaluated mRNA IGF2 expression in benign and malignant thyroid nodules, which showed a tendency for lower levels in nodular tissues (26).

IGFR in thyroid diseases. The characteristics of the included studies are described in Table II.

A study including 11 patients with MTC and 20 healthy controls demonstrated that serum IGF-1R levels were significantly higher in MTC (39). Another study including 


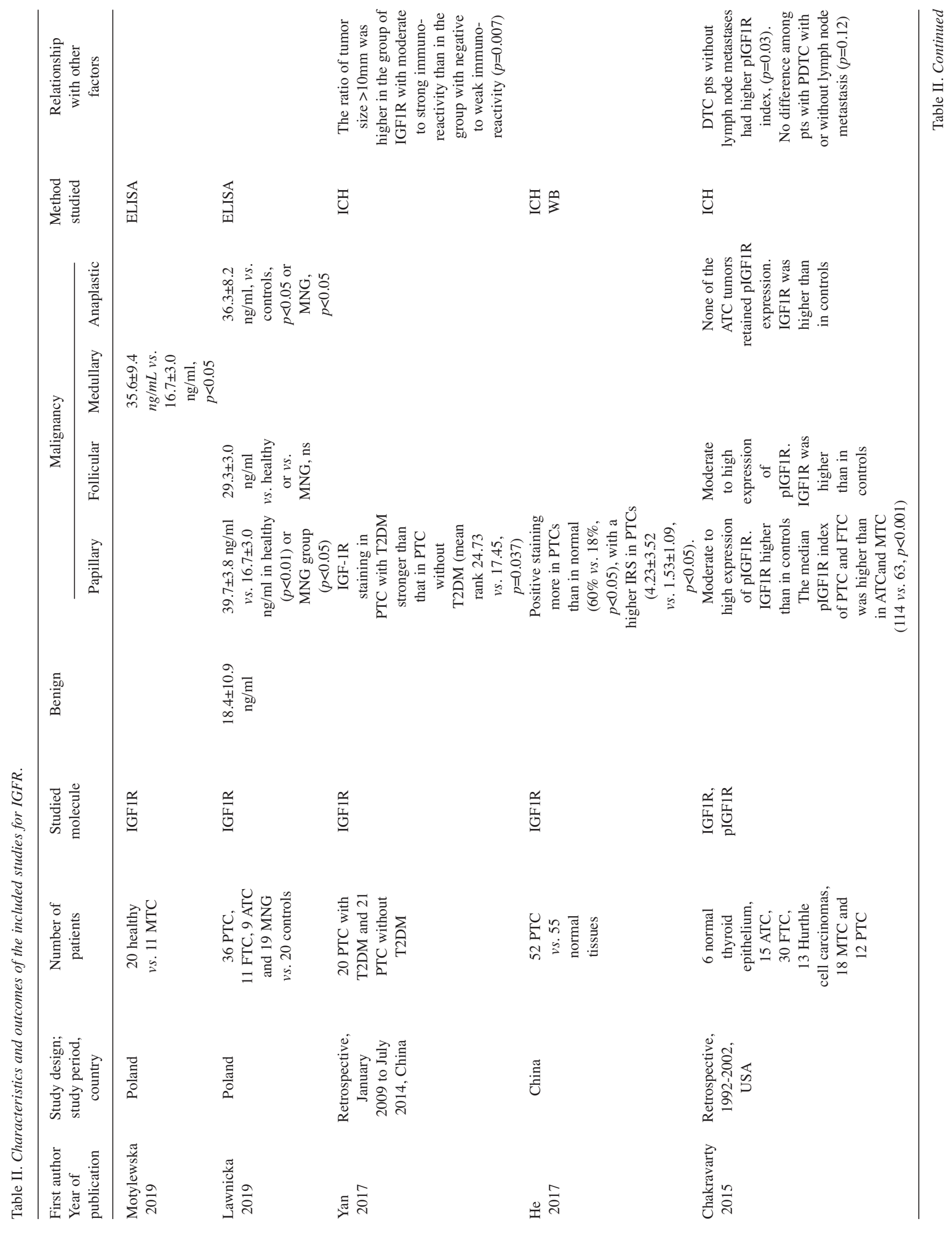




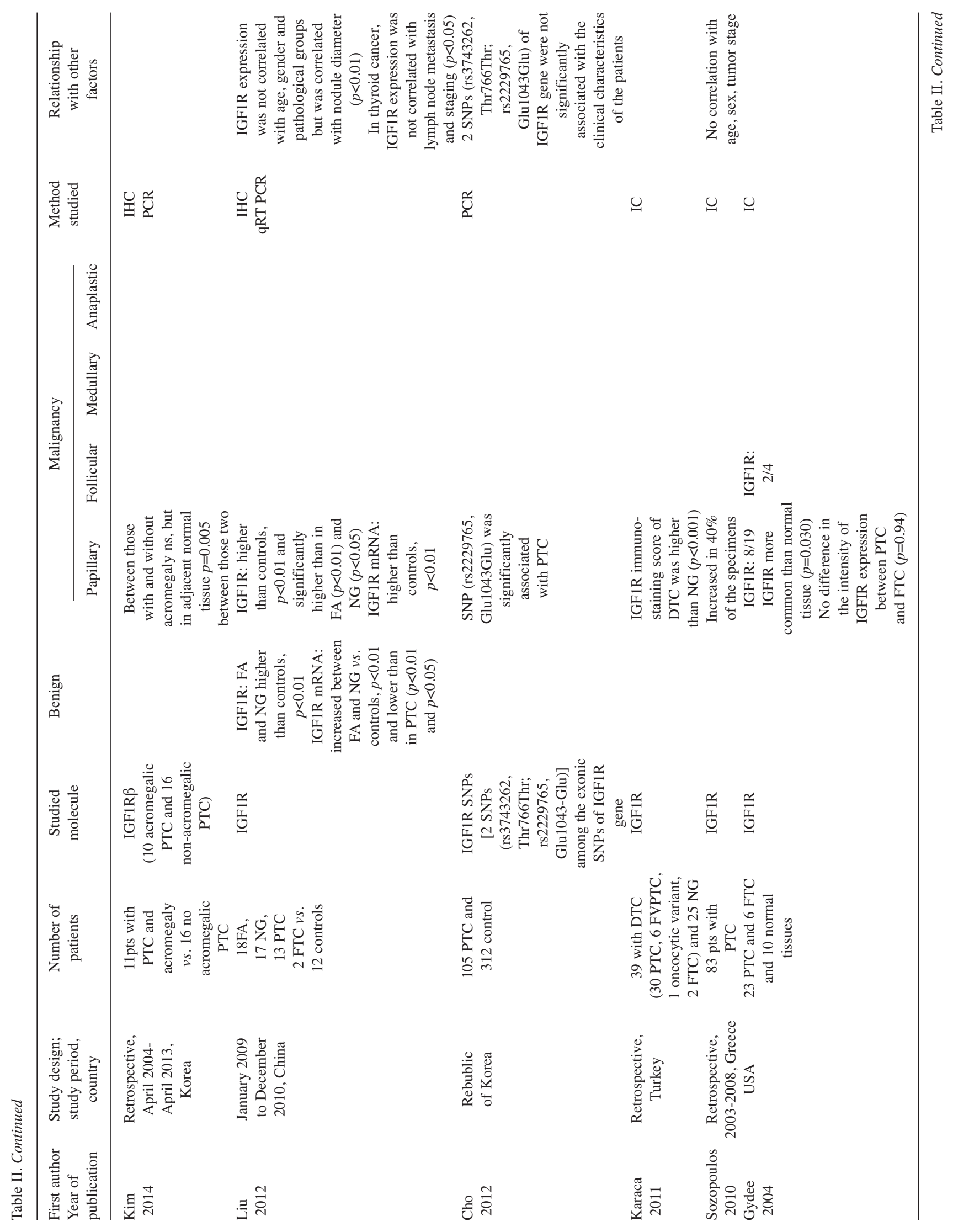




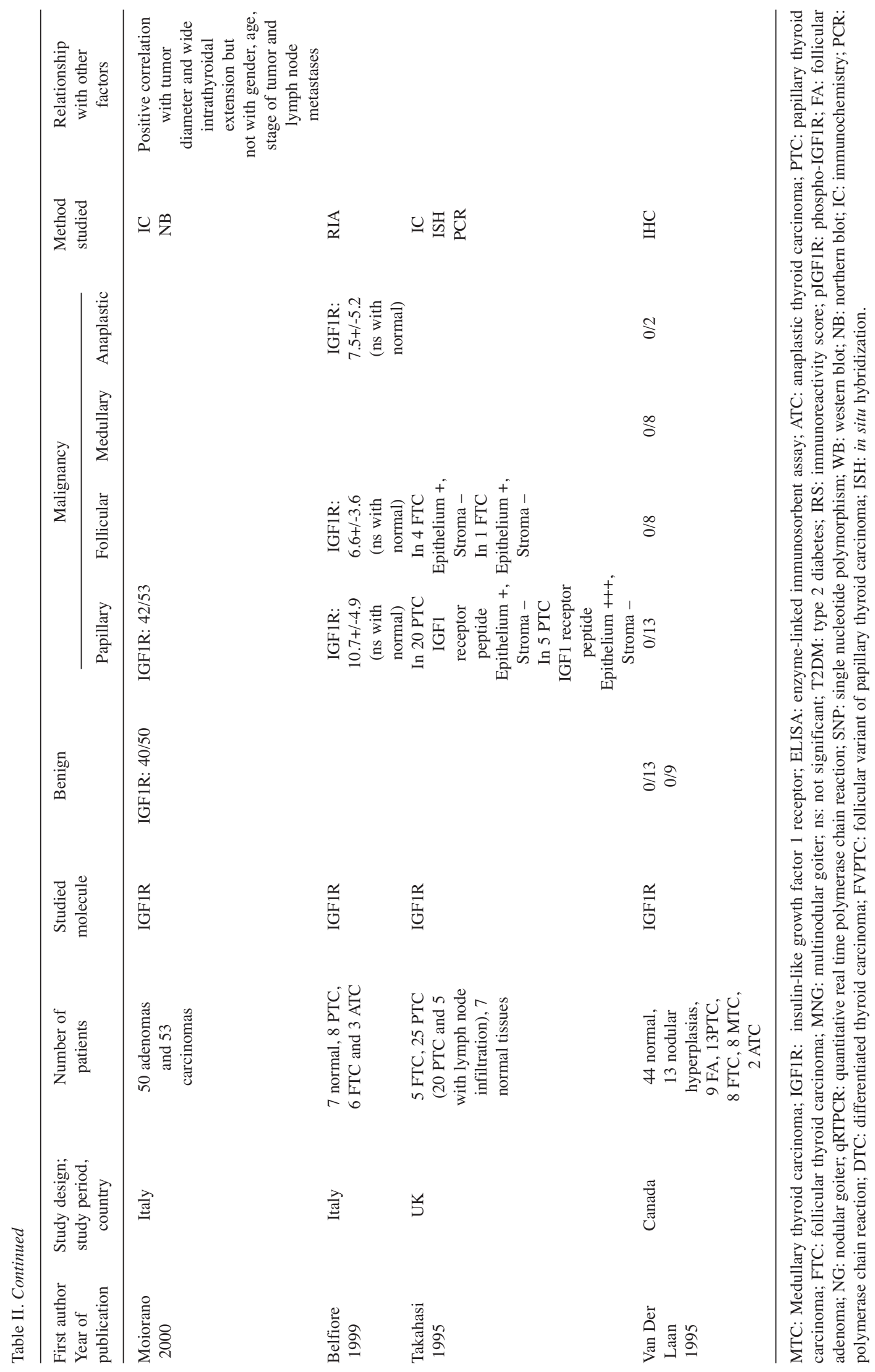


19 patients with multinodular nontoxic goiter, 36 with PTC, 11 with FTC, 9 with ATC and 20 controls, showed that IGF$1 \mathrm{R}$ levels are significantly higher in patients with PTC and ATC versus controls or multinodular nontoxic goiter (7).

Other studies have investigated the IGF-1R expression in subjects with PTC $(40,41)$. One of them aimed to compare the IGF-1R between patients with PTC and diabetes mellitus type II and patients with PTC but not diabetic (40). In the first group, the IGF-1R stained stronger than in the second one $(p=0.037)$. The tumor size was correlated significantly with the immunoreactivity of IGF-1R. In the other study, IGF1-R positive staining was found more frequently in PTCs with a higher immunoreactivity score than in healthy controls $(p<0.05)(41)$.

Chakravarty et al., studied i) 12 PTC, ii) 18 MTC, iii) 13 Hurtle cell carcinoma, iv) 30 FTC, v) 15 ATC and vi) 6 normal thyroid epithelium individuals (42). The expression of IGF-1R in malignant thyroid tissues was remarkably higher as compared to normal thyroid tissues, while its levels were significantly higher in PTC and FTC than ATC and MTC $(p<0.001)$. Lymph node metastasis was significantly correlated with lower IGF-1R levels in differentiated cancer, but there was no correlation in poorly differentiated carcinoma. Another trial has estimated the presence of IGF1 receptor $\beta$ (IGF-1R $\beta$ ) in acromegalic patients. According to their findings, IGF-1R $\beta$ levels were not differed significantly between PTC patients with or without acromegaly, but there was a significantly increased expression in adjacent normal tissue of those with acromegaly compared to those without (15). Liu et al., have found that IGF-1R levels were higher in tissues from patients with benign disease than in healthy tissues by both IHC and PCR analysis $(p<0.01)$, but its mRNA expression was significantly lower than PTC in follicular adenoma and nodular goiter $(p<0.01$ and $p<0.05$, respectively) (18). Additionally, IGF-1R levels were positively correlated with thyroid nodule diameter $(p<0.01)$, although in thyroid cancer there was no correlation with cervical lymph node metastasis and staging $(p<0.05)$. Patients with PTC versus controls were studied by Cho et al., who investigated 2 Single Nucleotide Polymorphisms (SNPs) of IGF-1R and found the rs2229765, Glu1043Glu to be significantly associated with PTC. The 2 SNPs were, however, not associated with clinical characteristics of the patients (43). Moreover, in another trial including 83 PCTs, IGF-1R levels were increased in $40 \%$ of the specimens and there was also no correlation with patient's characteristics or tumor stage (44). A separate study by Maiorano et al. showed increased levels of IGF-1R in both adenomas and carcinomas, as well as a positive correlation with tumor diameter and wide intrathyroidal extension (29).

The expression of IGF-1R in DTC and nodular goiter has also been explored. According to IHC analysis, a score was determined by a pathologist as i) grade 0: no staining, ii) grade 1: mild, iii) grade 2: moderate, iv) grade 3: intense staining. This study concluded that the IGF-1R immunostaining score was higher in patients with DTC compared to those with nodular goiter $(p<0.001)(22)$. When Gydee et al., compared the expression of IGF-1R between patients with PTC, FTC and normal controls under 21 years old by IHC, and found that the presence of IGF-1R was more common in PTCs than in normal tissues $(p=0.03)(27)$. There was no difference in immunostaining between PTCs and FTCs, but the expression of IGF-1R was significantly higher in more aggressive tumors $(p=0.029)$. Another study has demonstrated that IGF-1R is expressed in epithelium of PTCs and FTCs but not in the stroma (34).

Finally, a smaller study, in contrast with the previous ones, did not show any significant difference of IGF-1R expression between PTC, FTC and ATC and normal subjects (31). In addition, a study from Van Der Laan et al. in 1995 found no expression of IGF-1R in nodular hyperplasia and adenoma, PTCs, FTCs, ATCs and MTCs (35).

IGFBP in thyroid disease. The characteristics of the included studies are described in Table III.

A recent study investigated the presence of IGFBP7 in thyroid neoplasias and found that it was expressed in $66.7 \%$ and $65 \%$ of thyroid adenomas and PTCs, respectively, and in only $13.4 \%$ and $12.5 \%$ of FTCs and ATCs, respectively (45). IGFBP3 expression was studied in the Atlas' trial comparing men and women with benign thyroid disease (11). IGFBP3 serum levels were significantly higher than intranodular ones $(p=0.001)$. The intranodular levels were, however, significantly higher in subjects with multinodular goiter compared to those with single nodules $(p=0.043)$ while serum levels did not differ between the 2 groups. Additionally, there was a weak positive correlation between nodule size and IGFBP3 serum levels ( $p=0.042, \mathrm{r}=0.23)$. Pazaitou-Panayiotou et al. have studied 129 PTCs, 26 FTCs and 24 MTCs (13). They found that IGFBP3 levels were similar among different histological types or stages of thyroid cancer. Similar IGFBP3 levels have also been shown in another trial that compared 93 DTCs and 111 normal controls (47), where no correlation of IGFBP3 with TNM staging, tumor diameter or lymph node metastasis was found.

Another trial that included subjects with benign thyroid disease found no association between IGFBP3 and benign thyroid disorders (24). Xu et al., studied 4 SNPs in the promoter region of the IGFBP3 gene (rs2132571, rs2132572, rs2854744 and rs13241830) in 173 patients with DTC, 101 with BTD and 401 cancer-free controls (20). IGFBP3 rs2132572 was associated with decreased risk of BTD and DTC, while the rs2854744 genotype was associated with increased risk of both BTD and DTC. This correlation was more evident to those with a first-degree family history of cancer and to non-drinkers. 


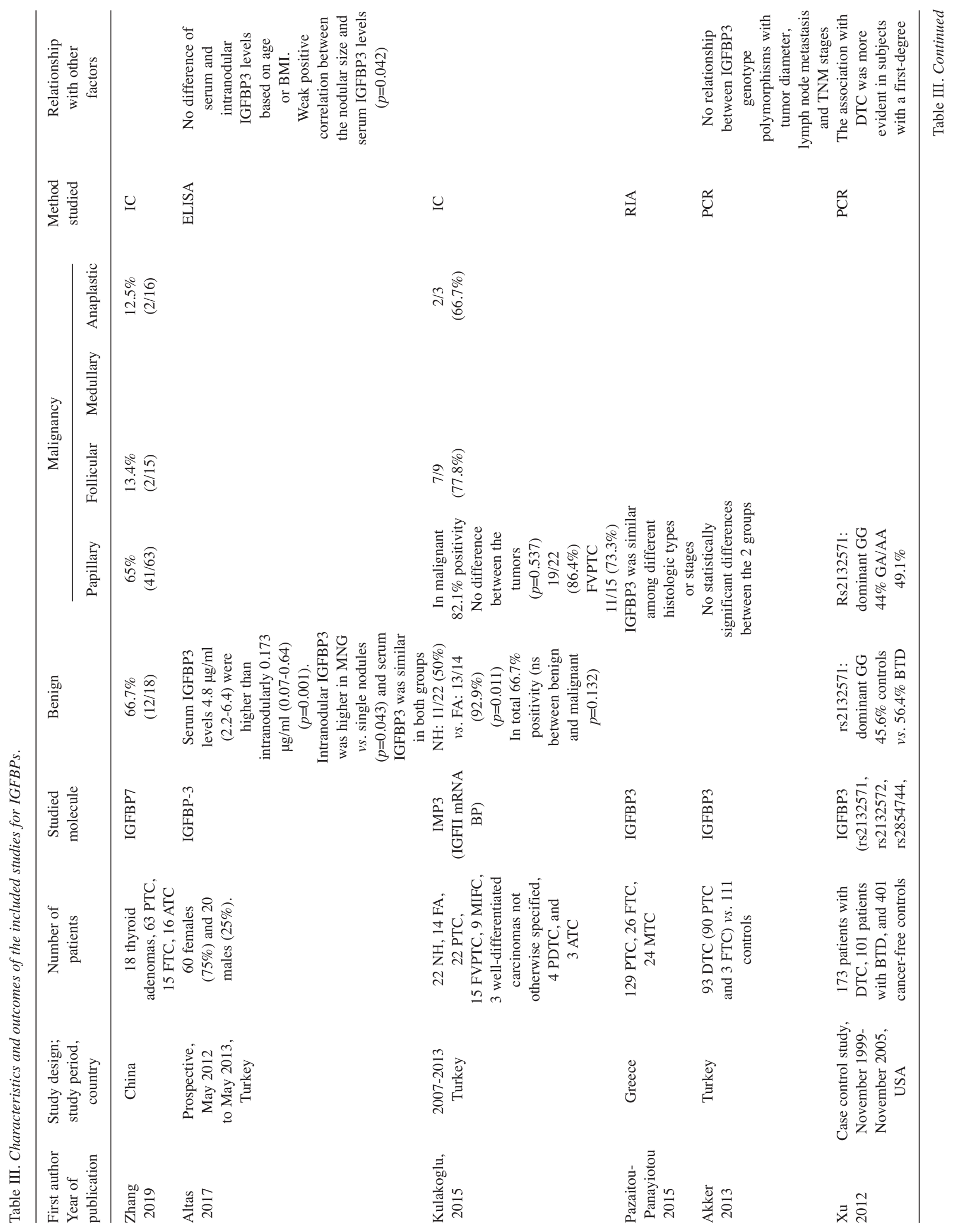




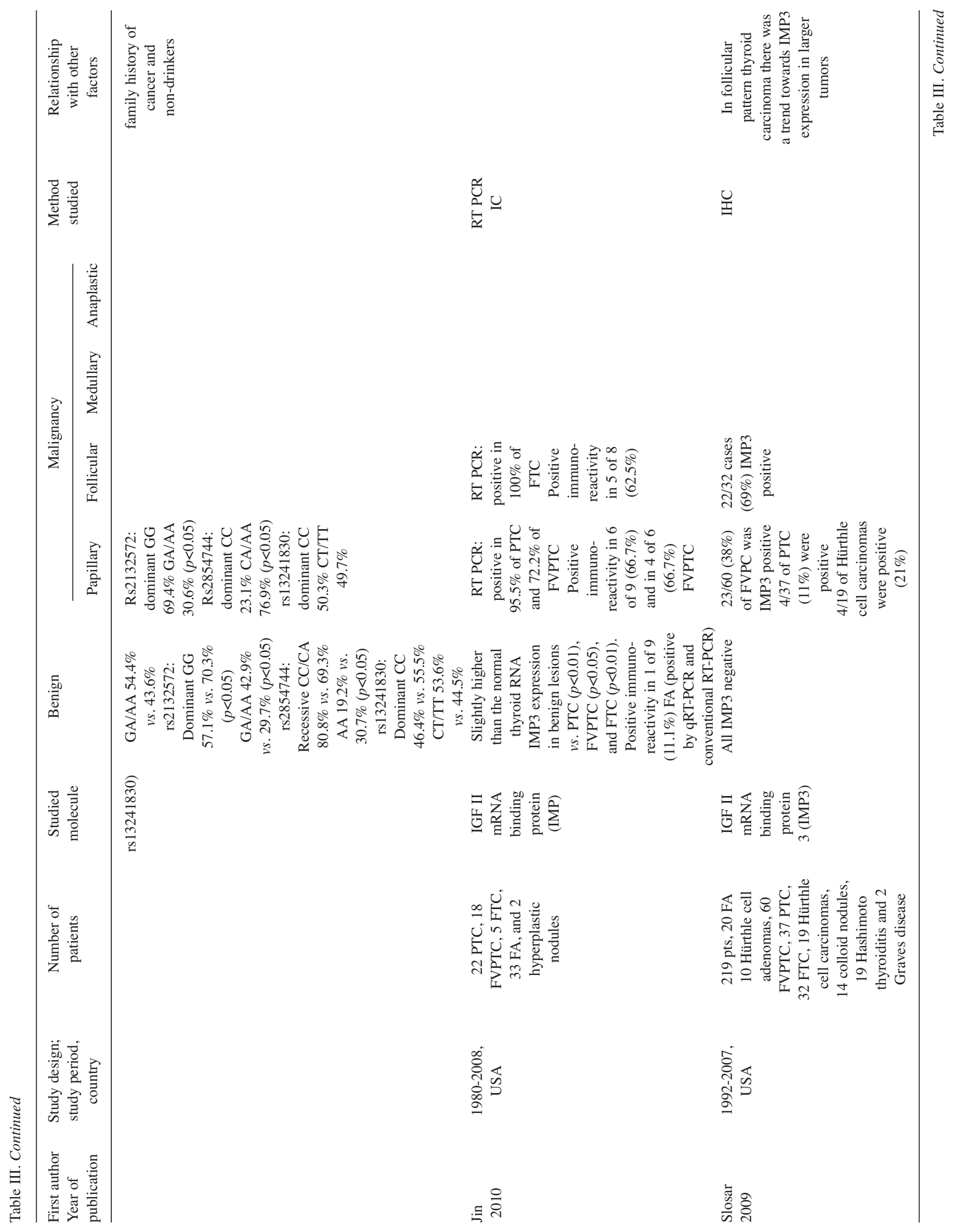




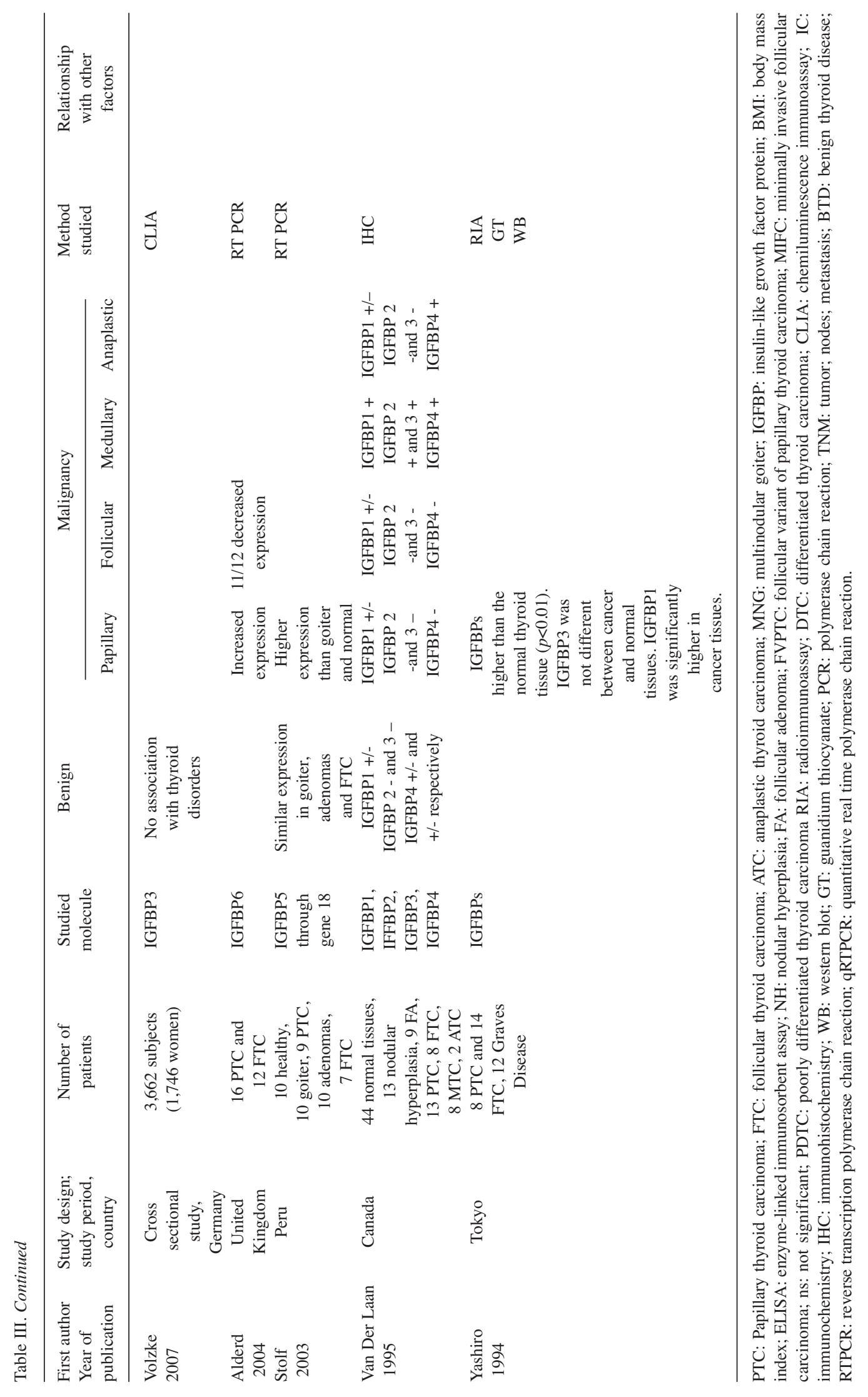


Kulakoglu et al. have shown that IMP3, a member of the IGF2 mRNA binding protein, was expressed in $50 \%$ of nodular hyperplasia, $92.9 \%$ of follicular adenoma, $82.1 \%$ of PTCs, $77.8 \%$ of FTCs and $66.7 \%$ of ATCs (46). The same molecule was studied by Jin et al. in 2010 (48). This group showed that IMP3 was slightly higher in follicular adenomas and hypeplastic nodules than in the normal thyroid cells, but significantly lower than PTCs $(p<0.01)$, follicular variants of papillary thyroid carcinomas (FVPTCs) $(p<0.05)$, and FTCs $(p<0.01)$. Its expression was increased in all PTCs and FTCs evaluated by both PCR (conventional and quantitative RTPCR) and IHC. Positive immunoreactivity for IMP3 was found in 10/15 PTCs and 5/8 FTCs. On the contrary, a study by Slosar et al. found that IMP3 was not expressed in all benign diseases examined, while it was expressed in $22 / 32$ of FTCs, only in 4/37 PTCs and in 23/60 FVPTCs (49).

Alderd et al. studied serum IGFBP6 levels in patients with PTC and FTC (50). According to them, IGFBP6 was increased in PTCs and decreased in all but one FTC. According to another study, IGFBP5 had similar expression in goiter adenoma and FTC and higher expression in PTCs compared to patients with goiter and normal tissues (51). Van Der Laan et al., have studied the expression of different IGFBPs in normal tissue, nodular hyperplasia, follicular adenoma, PTC, FTC, ATC and MTC (35). IGFBP3 stained positively only in MTCs, IGFBP4 in MTCs as well as in ATCs and in cases of nodular hyperplasia and IGFBP1 stained positively in MTCs and variably in benign lesions, PTCs, FTCs and ATCs. Finally, IGFBPs expression has been found higher in PCTs than in the normal thyroid tissue $(p<0.01)$ (36). Specifically, IGFBP3 did not differ between cancer and normal tissue, while IGFBP1 was higher in cancer, as evaluated by Western blot.

\section{Discussion}

IGF1 is a well-known growth factor involved in tumorigenesis. At the same time, the IGF bioregulation system plays a physiological role in the development of the thyroid gland $(52,53)$. Although, insulin and IGFs share common receptors and there is evidence that obese people with insulin resistance have increased incidence of thyroid cancer (53); however, the exact role of IGF1/2 in thyroid cancer has not been fully elucidated yet. In this study we investigated the role of IGF complex in thyroid tumors as well as in benign lesions.

In a study by Du et al., normal subjects had higher levels of IGF1 than the group with thyroid nodules and the incidence of nodules was higher when the IGF levels were lower (9). On the contrary, Basturk et al. as well as Liu et al. have both shown statistically significant higher IGF1 levels in thyroid nodules compared to the control group while Liu et al. have found increased levels of the IGF1 in solid adenomas compared to cystic lesions $(18,19,21)$. Volzke et al. designed a different study where they showed that among patients with benign thyroid pathology, the ones with higher IGF1 levels also presented with a higher probability for thyroid goiter and nodules (24). Another retrospective study by Atlas et al. showed that between a group with multinodular disease and a group with single nodular disease, the IGF1 as well as the IGFBP3 levels intranodularly were greater in the first group (11). In the same study, however, when they measured IGF1 and its binding protein levels in serum there were no differences between the two groups. Similarly, Rekvava et al., who investigated IGF1 levels in subjects with metabolic syndrome and nodules as well as subjects without metabolic syndrome found normal or lower levels of hyperinsulinemia, due to possible hyperglycemia in these patients (12). Perlino et al. ended up with similar results in the Atlas study demonstrating increased levels of IGF1 in multinodular disease compared to the control group (33). In a study by Dogan et al., acromegalic patients before receiving any therapeutic intervention had higher levels of IGF1 in the group with nodular disease compared to the control group, even though the relationship of IGF1 and thyroid nodules was not the primary endpoint in this study (17). Overall, the abovementioned results show a preferential expression of IGF1 in thyroid nodules, especially when they are solid and their number is greater than one. These results align with evidence obtained from other endocrine adenomas, such as adrenocortical $(54,55)$ as well as colorectal adenomas $(56)$, in which the expression of IGF1 is increased as compared to normal tissues. On the other hand, the study by Du et al. concluded in controversial results demonstrating a negative correlation between IGF1 expression and thyroid nodular disease; however, due to the fact that the nature of the nodules (benign or malignant) was not known this posed a limitation in the study (9). Nevertheless, in line with Du et al., Ersoy et al. showed lower IGF1 serum levels in children with goiter compared to children without goiter (57).

As far as thyroid cancer is concerned, most studies have concluded that the IGF molecular pathway is more highly expressed in thyroid cancer than in benign lesions and normal tissues. Specifically, IGF1 expression is higher in PTC according to the findings of a multicenter study with 345 patients enrolled (16). Moreover, according to Maiorano et al. as well as Pazaitou et al., IGF1 expression is higher and consistently related to tumor size and intrathyroidal invasion $(13,29)$, even though, in the later study the studied marker was not IGF1 alone, but a combination of IGF1, IGFBP and adiponectin. Of note, Asakawa et al. showed no detection of IGF1 in anaplastic and poorly differentiated thyroid carcinomas, on one hand highlighting the complexity of carcinogenesis in undifferentiated cancer and on the other pinpointing the preference of IGF1 expression in well 
differentiated cancer (32). This evidence is in line with studies in other types of cancer, such as colorectal, in which the tissue IGF1 expression gradually increases during disease progression from normal tissue to colorectal adenoma and finally to colon cancer (56). Similarly, serum IGF1 levels are significantly higher in patients with ovarian cancer compared to normal subjects (58).

Interestingly, only a few studies, such as the one by $\mathrm{Xu}$ et $a l$., have not found any significant differences in IGF1 levels among patients with differentiated thyroid cancer, benign nodules and healthy controls, while they have revealed a correlation between IGFBP3 levels and the risk for either benign lesion or differentiated thyroid cancer with a specific IGF1 polymorphism, respectively (20). In this study, the authors included ten different alleles for CA-repeat polymorphism in the promoter region of the $I G F-1$ gene and IGFBP3 polymorphisms that included four small SNPs in the promoter region of the IGFBP-3 gene. However, CA repeat polymorphism was not found to be a genetic biomarker for thyroid cancer susceptibility. Similarly, Karaca et al. have found no differences in serum IGF1 levels between patients with differentiated thyroid cancer and nodular goiter but these findings were not confirmed by an immunostaining score, which was significantly higher in patients with differentiated cancer (22).

Similar to the aforementioned studies, when PTC patients with or without acromegaly were compared, the obtained data showed statistically higher expression of IGF1 serum levels in the group of acromegalic patients (10). Tita et al. have shown similar IGF1 serum levels in acromegalic patients with and without DTC (25). However, when IHC analysis was performed, although the quantity of cells that stained for IGF1 did not differ among groups, in the group without acromegaly the intensity of staining was weak. Altogether, these studies show a possible tendency towards thyroid cancer when patients are exposed to higher IGF1 levels, such as in cases of acromegaly. Regarding the role of the $\mathrm{BRAF}^{\mathrm{V} 600 \mathrm{E}}$ mutation in the development of thyroid tumor, the results are controversial since the study by Kim et al. showed that this mutation does not play crucial role in the development of carcinogenesis in the acromegalic population, while a study by Mian et al. showed that the thyroid cancer risk was associated with $\mathrm{BRAF}^{\mathrm{V} 600 \mathrm{E}}$, further implying that the GH/IGF system cannot trigger thyroid tumorigenesis by itself $(14,15)$.

Of note, two studies have evaluated the expression of molecules that share great similarity to IGF1. Karagiannis et $a l$. have studied an isoform of IGF1, the IGF1Ec, which is derived by alternative splicing in the igf gene during the transcriptional process (8). This study demonstrated the expression of the Ec isoform in differentiated thyroid carcinoma, positively correlating with TNM staging, muscular and capsular invasion. Similar results regarding the expression of the IGF1Ec variant were also obtained in prostate cancer (59). A study by Fuhren et al. have measured decreased mRNA expression of IGF2 in thyroid nodules, both benign and malignant, compared to normal thyroid tissue (26).

Regarding the receptor of IGF, the majority of studies has concluded that it is highly expressed in DTC. Moreover, a study by Gydde et al. have demonstrated higher levels of IGF-1R in children with DTC positively correlating with the aggressiveness of the tumor (27). Despite this, Liu et al. have shown higher mRNA expression of the receptor in malignant tumors compared to benign lesions (18), positively correlated with the tumor nodule diameter. This is in contrast with the majority of papers, where there is no positive correlation with either staging or lymph node metastasis. Indeed, in a study by Chakravarty et al., lymph node metastasis correlated with lower levels of IGF1 in DTC, while no correlation was found with poorly differentiated thyroid carcinoma (42). This evidence possibly demonstrates the complexity of metastatic process, which is perhaps IGF1/IGFR-independent.

According to the majority of studies, undifferentiated and medullary carcinoma does not express the IGF receptor. However, Motylewska et al. have demonstrated its expression in MTC (7) and Lawnicka et al. in ATC and PTC, (39), while Chakravarty et al. in all types of cancer (42). Notably, IGF-1R expression was higher in DTC compared to anaplastic carcinoma (42). In contrast to all previous studies, a study from Canada in 1995 found no IGF-1R expression in either benign or malignant tissues (35), while others may have confirmed its expression, but with no significant differences among normal tissues, differentiated and anaplastic tumors (31). The expression of IGF-1R has been localized either in the epithelium or in the stroma of thyroid cancer cells (34). Faical et al., have demonstrated mainly cytoplasmic and less perinuclear staining for the receptor, which is in agreement with its pattern in other endocrine organs, such as the adrenal gland (55). Moreover, IGF-1R staining seems to be stronger when diabetes mellitus type 2 is present (40), possibly due to the concomitant hyperinsulinemia and hyperglycemia.

The IGFBP family consists of 7 proteins and most of them have already been studied in thyroid cancer as well as in benign nodular disease. In general, most studies have shown higher expression of IGFBPs in cancer and especially in DTC compared to benign nodular disease and normal thyroid tissue. Regarding the type of carcinoma, Van Der Laan et al. show that the expression of IGFBPs is persistently higher in MTC and variable in other types of thyroid cancer (35), which, for IGFBP2-3 this could be expected since these isoforms are produced by neuroendocrine cells (60). IGFBP3 levels have appeared similar among different types of thyroid cancer in two trials $(13,47)$, while IGFBP3 has not been 
found to correlate with benign lesions (24). IGFBP7 seems to be expressed more in PTC than in other types of thyroid cancer as well as in thyroid adenomas (45). Similar results were excluded from 3 other publications that studied IMP3, a member of IGF2 mRNA binding protein $3(46,48,49)$.

In conclusion, the IGF complex is involved in thyroid development and seems to play an important role in thyroid cancer. IGF1, rather than IGF2, is preferentially expressed in nodular thyroid disease and especially when the nodule is solid or more than one. Regarding thyroid cancer, there is an enhanced expression of IGF-1 system in DTC compared to MTC and ATC. Moreover, IGF1 receptor staining is more intense in PTC than in other types of thyroid cancer and mainly cytoplasmic. IGFBPs are also mostly expressed in differentiated thyroid carcinoma, and specifically in PTC. Altogether, several studies point towards an important role of IGF system in thyroid disease since it is expressed in both benign and malignant thyroid nodules, however, the conclusions should be interpreted with caution: i) the IGF system and its relationship with thyroid cancer was not the primary endpoint in all the studies and in some cases it was just measured among other molecules; ii) the method used to evaluate the expression of the molecules involved in the IGF system varied between studies (i.e. RT-PCR, IHC, Elisa etc.); iii) due to the rarity of undifferentiated tumors, conclusions cannot be drawn for anaplastic and poor differentiated carcinomas. Furthermore, we included studies with different design and size population varying from twenty patients to multicenter studies with hundreds of patients. Well-designed large clinical studies with the relation of IGF system with the thyroid neoplasm as a primary endpoint as well as ongoing basic research pertinent to the pathophysiological role of this system may lead to the development of useful diagnostic and therapeutic tools in the future.

\section{Conflicts of Interest}

The Authors declare no conflicts of interest.

\section{Authors' Contributions}

AK designed and performed the study, analyzed data and wrote the manuscript; EK and AC wrote and reviewed the manuscript; and MK conceived and designed the study, analyzed the data and reviewed the manuscript. All Authors have read and approved the final manuscript.

\section{References}

1 Gardner DG and Shoback D: Greenspan's Clinical and Basic Endocrinology, LANGE Clinical Medicine, $9^{\text {th }}$ edition.

2 Shlomo Melmed S, Kenneth Polonsky KS, Larsen R and Kronenberg H: Williams textbook of endocrinology. Elsevier, Philadelphia, 13 ${ }^{\text {nd }}$ Edition, 2016.
3 Samani AA, Yakar S, LeRoith D and Brodt P: The role of the IGF system in cancer growth and metastasis: Overview and recent insights. Endocr Rev 28(1): 20-47, 2007. PMID: 16931767. DOI: 10.1210/er.2006-0001

4 Philippou A, Christopoulos PF and Koutsilieris DM: Clinical studies in humans targeting the various components of the IGF system show lack of efficacy in the treatment of cancer. Mutat Res Rev Mutat Res 772: 105-122, 2016. PMID: 28528684. DOI: 10.1016/j.mrrev.2016.09.005

5 Manzella L, Massimino M, Stella S, Tirrò E, Pennisi MS, Martorana F, Motta G, Vitale SR, Puma A, Romano C, di Gregorio S, Russo M, Malandrino P and Vinieri P: Activation of the IGF axis in thyroid cancer: Implications for tumorigenesis and treatment. Int J Mol Sci 20(13), 2019. PMID: 31269742. DOI: $10.3390 /$ ijms20133258

6 Philippou A, Maridaki M, Pneumaticos S and Koutsilieris M: The complexity of the IGF1 gene splicing, posttranslational modification and bioactivity. Mol Med 20(1): 202-214, 2014. PMID: 24637928. DOI: 10.2119/molmed.2014.00011

7 Lawnicka H, Motylewska E, Borkowska M, Kuzdak K, Siejka A, Swietoslawski, Stepien H and Stepien T: Elevated serum concentrations of IGF-1 and IGF-1R in patients with thyroid cancers. Biomed Pap Med Fac Univ Palacky Olomouc Czech Repub 164(1): 77-83, 2020. PMID: 31132076. DOI: 10.5507/ bp.2019.018

8 Karagiannis AK, Philippou A, Tseleni-Balafouta S, Zevolis E, Nakouti T, Tsopanomichalou-Gklotsou M, Psarras V and Koutsilieris M: IGF-IEc expression is associated with advanced differentiated thyroid cancer. Anticancer Res 39(6): 2811-2819, 2019. PMID: 31177118. DOI: 10.21873/anticanres.13409

9 Du P, Liu F, Liu Y, Shao M, Li X and Qin G: Linc00210 enhances the malignancy of thyroid cancer cells by modulating miR-195-5p/IGF1R/Akt axis. J Cell Physiol 235(2): 1001-1012, 2020. PMID: 31240707 . DOI: 10.1002/jcp.29016

10 Keskin FE, Ozkaya HM, Ferahman S, Haliloglu O, Karatas A, Aksoy F and Kadioglu P: The role of different molecular markers in papillary thyroid cancer patients with acromegaly. Exp Clin Endocrinol Diabetes 127(7): 437-444, 2019. PMID: 29890543. DOI: 10.1055/a-0629-9223

11 Altas A, Kuzu F, Arpaci D, Unal M, Can M, Barut F, Kokturk F, Ilikhan SU and Bayraktaroglu T: The clinical values of insulinlike growth factor-1 and insulin-like growth factor binding protein-3 levels in blood and thyroid nodules. Int J Endocrinol, 2017. PMID: 29081797. DOI: 10.1155/2017/3145234

12 Rekvava M, Dundua T, Kobulia M, Javashvili L and Giorgadze E: Insulin like growth factor 1 possible dependence in patients with metabolic syndrome of nodular pathology of the thyroid gland. Georgian Med News (270): 46-50, 2017. PMID: 28972482.

13 Pazaitou-Panayiotou K, Panagiotou G, Polyzos SA and Mantzoros CS: Serum adiponectin and insulin-like growth factor 1 in predominantly female patients with thyroid cancer: association with the histologic characteristics of the tumor. Endocr Pract. 22(1): 68-75, 2016. PMID: 26484409. DOI: 10.4158/EP15814.OR

14 Mian C, Ceccato F, Barollo S, Watutantrige-Fernando S, Albiger N, Regazzo D, de Lazzari P, Pennelli G, Rotondi S, Nacamulli D, Pelizzo MR, Jaffrain-Rea ML, Grimaldi F, Occhi G and Scaroni C: AHR over-expression in papillary thyroid carcinoma: clinical and molecular assessments in a series of Italian acromegalic patients with a long-term follow-up. PLoS One 
9(7): e101560, 2014. PMID: 25019383. DOI: 10.1371/journal. pone. 0101560

15 Kim HK, Lee JS, Park MH, Cho JS, Yoon JH, Kim SJ and Kang $\mathrm{HC}$ : Tumorigenesis of papillary thyroid cancer is not BRAFdependent in patients with acromegaly. PLoS One 9(10): e110241, 2014. PMID: 25329702. DOI: 10.1371/journal.pone.0110241

16 Schmidt JA, Allen NE, Almquist M, Franceschi S, Rinaldi S, Tipper SJ, Tsilidis KK, Weiderpass E, Overvad K, Tjønneland A, Boutron-Ruault MC, Dossus L, Mesrine S, Kaaks R, Lukanova A, Boeing H, Lagiou P, Trichopoulos D, Trichopoulou A, Palli D1 Krogh V, Panico S, Tumino R, Zanetti R, Bueno-deMesquita HB, Peeters PH, Lund E, Menéndez V, Agudo A, Sánchez MJ, Chirlaque MD, Ardanaz E, Larrañaga N, Hennings J, Sandström M, Khaw KT, Wareham N, Romieu I, Gunter MJ, Riboli E, Key TJ and Travis RC: Insulin-like growth factor-i and risk of differentiated thyroid carcinoma in the European prospective investigation into cancer and nutrition. Cancer Epidemiol Biomarkers Prev 23(6): 976-985, 2014. PMID: 24646451. DOI: 10.1158/1055-9965.EPI-13-1210-T

17 Dogan S, Atmaca A, Dagdelen S, Erbas B and Erbas T: Evaluation of thyroid diseases and differentiated thyroid cancer in acromegalic patients. Endocrine 45(1): 114-121, 2014. PMID: 23670709. DOI: 10.1007/s12020-013-9981-3

18 Liu YJ, Qiang W, Shi J, Lv SQ, Ji MJ and Shi BY: Expression and significance of IGF-1 and IGF-1R in thyroid nodules. Endocrine 44(1): 158-164, 2013. PMID: 23288662. DOI: 10.1007/s12020-012-9864-z

19 Baştürk E, Kement M, Yavuzer D, Vural S, Gezen C, Gözü HI, Karadayı A and Oncel M: The role of insulin-like growth factor 1 in the development of benign and malignant thyroid nodules. Balkan Med J 29(2): 133-138, 2012. PMID: 25206982. DOI: 10.5152/balkanmedj.2011.034

$20 \mathrm{Xu} \mathrm{L}$, Mugartegui L, Li G, Sarlis NJ, Wei Q, Zafereo ME and Sturgis EM: Functional polymorphisms in the insulin-like binding protein-3 gene may modulate susceptibility to differentiated thyroid carcinoma in Caucasian Americans. Mol Carcinog 51 Suppl 1: E158-167, 2012. PMID: 22415807. DOI: $10.1002 / \mathrm{mc} .21900$

21 Liu YJ, Qiang W, Liu XJ, Xu L, Guo H, Wu LP and Shi B: Association of insulin-like growth factor-1 with thyroid nodules. Oncol Lett 2(6): 1297-1301, 2011. PMID: 22848305. DOI: 10.3892/ol.2011.411

22 Karaca Z, Tanriverdi F, Unluhizarci K, Ozturk F, Gokahmetoglu S, Elbuken G, Cakir I, Bayram F and Kelestimur F: VEGFR1 expression is related to lymph node metastasis and serum VEGF may be a marker of progression in the follow-up of patients with differentiated thyroid carcinoma. Eur J Endocrinol 164(2): 277284, 2011. PMID: 21097568. DOI: 10.1530/EJE-10-0967

23 Gullu BE, Celik O, Gazioglu N and Kadioglu P: Thyroid cancer is the most common cancer associated with acromegaly. Pituitary 13(3): 242-248, 2010. PMID: 20217483. DOI: 10.1007/s11102010-0224-9

24 Völzke H, Friedrich N, Schipf S, Haring R, Lüdemann J, Nauck M, Dörr M, Brabant G and Wallaschofski H: Association between serum insulin-like growth factor-I levels and thyroid disorders in a population-based study. J Clin Endocrinol Metab 92(10): 40394045, 2007. PMID: 17666480. DOI: 10.1210/jc.2007-0816

25 Tita P, Ambrosio MR, Scollo C, Carta A, Gangemi P, Bondanelli M, Vigneri R, degli Uberti EC and Pezzino V: High prevalence of differentiated thyroid carcinoma in acromegaly. Clin
Endocrinol (Oxf) 63(2): 161-167, 2005. PMID: 16060909. DOI: 10.1111/j.1365-2265.2005.02316.x

26 Fuhrer D, Eszlinger M, Karger S, Krause K, Engelhardt C, Hasenclever D, Dralle H and Paschke R: Evaluation of insulinlike growth factor II, cyclooxygenase-2, ets-1 and thyroidspecific thyroglobulin mRNA expression in benign and malignant thyroid tumours. Eur J Endocrinol 152(5): 785-790, 2005. PMID: 15879365. DOI: 10.1530/eje.1.01912

27 Gydee H, O'Neill JT, Patel A, Bauer AJ, Tuttle RM and Francis GL: Differentiated thyroid carcinomas from children and adolescents express IGF-I and the IGF-I receptor (IGF-I-R). Cancers with the most intense IGF-I-R expression may be more aggressive. Pediatr Res 55(4): 709-715, 2004. PMID: 14973173. DOI: 10.1203/01.PDR.0000111282.98401.93

28 Veselý D, Astl J, Lastůvka P, Matucha P, Sterzl I and Betka J: Serum levels of IGF-I, HGF, TGFbeta1, bFGF and VEGF in thyroid gland tumors. Physiol Res 53(1): 83-89, 2004. PMID: 14984318.

29 Maiorano E, Ciampolillo A, Viale G, Maisonneuve P, Ambrosi A, Triggiani V, Marra E and Perlino E: Insulin-like growth factor 1 expression in thyroid tumors. Appl Immunohistochem Mol Morphol 8(2): 110-119, 2000. PMID: 10937058. DOI: 10.1097/ 00129039-200006000-00005

30 Silva Filho GB, Maciel RM, Takahashi MH, Alberti VN, Castro IV, Saldiva PH, Durazzo MD and Ferraz AR: Study of immunohistochemical expression of insulin-like growth factor I and proliferating cell nuclear antigen in thyroid gland papillary carcinoma and its metastasis. Head Neck 21(8): 723-727, 1999. PMID: 10562685. DOI: 10.1002/(sici)1097-0347(199912)21: 8<723::aid-hed7>3.0.co;2-6

31 Belfiore A, Pandini G, Vella V, Squatrito S and Vigneri R: Insulin/IGF-I hybrid receptors play a major role in IGF-I signaling in thyroid cancer. Biochimie 81(4): 403-407, 1999. PMID: 10401676. DOI: 10.1016/s0300-9084(99)80088-1

32 Asakawa $\mathrm{H}$ and Kobayashi T: The secretion of cytokines and granulocyte colony stimulating factor by anaplastic and poorly differentiated thyroid carcinoma cell lines. Anticancer Res 19(1B): 761-764, 1999. PMID: 10216489.

33 Perlino E, Ciampolillo A, Maenza S, Marra E, Derobertis O, Ambrosi A, Giorgino $\mathrm{R}$ and Quagliariello E: Increased expression of insulin-like growth factor 1 (IGF-1) in multinodular non toxic goiter. Oncol Rep 3(4): 753-757, 1996. PMID: 21594449. DOI: 10.3892/or.3.4.753

34 Takahashi MH1, Thomas GA and Williams ED: Evidence for mutual interdependence of epithelium and stromal lymphoid cells in a subset of papillary carcinomas. Br J Cancer 72(4): 813817, 1995. PMID: 7547225. DOI: 10.1038/bjc.1995.418

35 van der Laan BF1, Freeman JL and Asa SL: Expression of growth factors and growth factor receptors in normal and tumorous human thyroid tissues. Thyroid 5(1): 67-73, 1995. PMID: 7787437. DOI: 10.1089/thy.1995.5.67

36 Yashiro T, Arai M, Shizume K, Obara T, Murakami H, Hizuka N, Emoto N, Miyakawa M, Ito K and Tsushima T: Increased activity of insulin-like growth factor-binding protein in human thyroid papillary cancer tissue. Jpn J Cancer Res 85(1): 46-52, 1994. PMID: 7508906. DOI: 10.1111/j.1349-7006.1994.tb02885.x

37 Masood S, Auguste LJ, Westerband A, Belluco C, Valderama E and Attie J: Differential oncogenic expression in thyroid follicular and Hürthle cell carcinomas. Am J Surg 166(4): 366-368, 1993. PMID: 8214294. DOI: 10.1016/s0002-9610(05)80334-4 
38 Minuto F, Barreca A, Del Monte P, Cariola G, Torre GC and Giordano G: Immunoreactive insulin-like growth factor I (IGFI) and IGF-I-binding protein content in human thyroid tissue. J Clin Endocrinol Metab 68(3): 621-626, 1989. PMID: 2537339. DOI: $10.1210 /$ jcem-68-3-621

39 Motylewska E, Borkowska M, Ławnicka H, Kuzdak K, Siejka A, Świętosławski J, Stepien H and Stepien T: Dysregulation in IGF-1R, FGFR4 and $\beta$ Klotho signaling in patients with medullary thyroid cancer. Neuro Endocrinol Lett 40(1): 29-35, 2019. PMID: 31184820.

40 Yan $\mathrm{Y}, \mathrm{Hu} \mathrm{F}, \mathrm{Wu} \mathrm{W}, \mathrm{Ma} \mathrm{R}$ and Huang $\mathrm{H}$ : Expression characteristics of proteins of IGF-1R, p-Akt, and survivin in papillary thyroid carcinoma patients with type 2 diabetes mellitus. Medicine (Baltimore) 96(12): e6393, 2017. PMID: 28328831. DOI: 10.1097/MD.0000000000006393

41 He L, Zhang S, Zhang X, Liu R, Guan H and Zhang H: Effects of insulin analogs and glucagon-like peptide-1 receptor agonists on proliferation and cellular energy metabolism in papillary thyroid cancer. Onco Targets Ther 10: 5621-5631, 2017. PMID: 29200876. DOI: $10.2147 /$ OTT.S150701

42 Chakravarty G, Santillan AA, Galer C, Adams HP, El-Naggar AK, Jasser SA, Mohsin S, Mondal D, Clayman GL and Myers JN: Phosphorylated insulin like growth factor-I receptor expression and its clinico-pathological significance in histologic subtypes of human thyroid cancer. Exp Biol Med (Maywood) 234(4): 372386, 2009. PMID: 19176870. DOI: 10.3181/0809-RM-284

43 Cho SH1, Kim SK, Kwon E, Park HJ, Kwon KH and Chung JH: Polymorphism of IGF1R is associated with papillary thyroid carcinoma in a Korean population. J Interferon Cytokine Res 32(9): 401-406, 2012. PMID: 22909219. DOI: 10.1089/jir. 2011.0084

44 Sozopoulos E, Litsiou H, Voutsinas G, Mitsiades N, Anagnostakis N, Tseva T, Patsouris E and Tseleni-Balafouta S: Mutational and immunohistochemical study of the PI3K/Akt pathway in papillary thyroid carcinoma in Greece. Endocr Pathol 21(2): 90100, 2010. PMID: 20186503. DOI: 10.1007/s12022-010-9112-0

45 Zhang L, Lian R, Zhao J, Feng X, Ye R, Pan L, Wu J, Li M, Huan $\mathrm{Y}$ and Cai J: IGFBP7 inhibits cell proliferation by suppressing AKT activity and cell cycle progression in thyroid carcinoma. Cell Biosci 9: 44, 2019. PMID: 31183073. DOI: 10.1186/s13578-019-0310-2

46 Kulaçoğlu S and Erkılınç G: Imp3 expression in benign and malignant thyroid tumors and hyperplastic nodules. Balkan Med J 32(1): 30-37, 2015. PMID: 25759769. DOI: 10.5152/ balkanmedj.2015.15547

47 Akker M, Güldiken S, Sipahi T, Palabıyık O, Tosunoğlu A, Çelik Ö, Tunçbilek N, Sezer A and Süt N: Investigation of insulin resistance gene polymorphisms in patients with differentiated thyroid cancer. Mol Biol Rep 41(5): 3541-3547, 2014. PMID: 24504452. DOI: $10.1007 / \mathrm{s} 11033-014-3218-2$

48 Jin L, Seys AR, Zhang S, Erickson-Johnson MR, Roth CW, Evers BR, Oliveira AM and Lloyd RV: Diagnostic utility of IMP3 expression in thyroid neoplasms: a quantitative RT-PCR study. Diagn Mol Pathol 19(2): 63-69, 2010. PMID: 20502182. DOI: 10.1097/PDM.0b013e3181b6a528

49 Slosar M, Vohra P, Prasad M, Fischer A, Quinlan R and Khan A: Insulin-like growth factor mRNA binding protein 3 (IMP3) is differentially expressed in benign and malignant follicular patterned thyroid tumors. Endocr Pathol 20(3): 149-157, 2009. PMID: 19449140. DOI: 10.1007/s12022-009-9079-x
50 Aldred MA, Huang Y, Liyanarachchi S, Pellegata NS, Gimm O, Jhiang S, Davuluri RV, de la Chapelle A and Eng C: Papillary and follicular thyroid carcinomas show distinctly different microarray expression profiles and can be distinguished by a minimum of five genes. J Clin Oncol 22(17): 3531-3539, 2004. PMID: 15337802 . DOI: 10.1200/JCO.2004.08.127

51 Stolf BS, Carvalho AF, Martins WK, Runza FB, Brun M, Hirata R Jr, Jordão Neves E, Soares FA, Postigo-Dias J, Kowalski LP and Reis LF: Differential expression of IGFBP-5 and two human ESTs in thyroid glands with goiter, adenoma and papillary or follicular carcinomas. Cancer Lett 191(2): 193-202, 2003. PMID: 12618333. DOI: 10.1016/s0304-3835(02)00679-1

52 Dumont JE, Lamy F, Roger P and Maenhaut C: Physiological and pathological regulation of thyroid cell proliferation and differentiation by thyrotropin and other factors. Physiol Rev 72(3): 667-697, 1992. PMID: 1320763. DOI: 10.1152/physrev.1992.72.3.667

53 Malaguarnera R, Frasca F, Garozzo A, Gianì F, Pandini G, Vella $\mathrm{V}$, Vigneri $\mathrm{R}$ and Belfiore $\mathrm{A}$ : Insulin receptor isoforms and insulin-like growth factor receptor in human follicular cell precursors from papillary thyroid cancer and normal thyroid. J Clin Endocrinol Metab 96(3): 766-774, 2011. PMID: 21123448. DOI: $10.1210 /$ jc.2010-1255

54 Cantini G, Lombardi A, Piscitelli E, Poli G, Ceni E, Marchiani S, Ercolino T, Galli A, Serio M, Mannelli M and Luconi M: Rosiglitazone inhibits adrenocortical cancer cell proliferation by interfering with the IGF-IR intracellular signaling. PPAR Res, 2008. PMID: 18670617. DOI: 10.1155/2008/904041

55 Faical S, Rui Maciel RMB, Nose-Alberti V, Santos MC and Kater CE: Immunodetection of insulin-like growth factor I (IGF1) in normal and pathological adrenocortical tissue. Endocr Pathol Spring 9(1): 63-70, 1998. PMID: 12114663. DOI: 10.1007/BF02739953

56 Hakam A, Yeatman TJ, Lu L, Mora L, Marcet G, Nicosia SV, Karl RC and Coppola D: Expression of insulin-like growth factor-1 receptor in human colorectal cancer. Hum Pathol 30(10): 1128-1133, 1999. PMID: 10534157. DOI: 10.1016/ s0046-8177(99)90027-8

57 Ersoy B, Gunes HS, Uyanik BS, Taneli F and Gunay T: Interactions of thyroid hormones; insulin-like growth factor-1 (IGF-1), IGF binding proteins, and nutritional anthropometric parameters in school children with goiter detected by palpation. Exp Clin Endocrinol Diabetes 117(9): 490-495, 2009. PMID: 19876794. DOI: $10.1055 / \mathrm{s}-0029-1237732$

58 Lukanova A, Lundin E, Toniolo P, Micheli A, Akhmedkhanov A, Rinaldi S Muti P, Lenner P, Biessy C, Krogh V, ZeleniuchJacquotte A, Berrino F, Hallmans G, Riboli E and Kaaks R: Circulating levels of insulin-like growth factor-I and risk of ovarian cancer. Int J Cancer 101(6): 549-554, 2002. PMID: 12237896. DOI: $10.1002 / \mathrm{ijc} .10613$

59 Philippou A, Armakolas A and Koutsilieris M: Evidence for the possible biological significance of the Igf-1 gene alternative splicing in prostate cancer. Front Endocrinol (Lausanne) 4: 31, 2013. PMID: 23519101. DOI: 10.3389/fendo.2013.00031

60 Sara VR and Hall K: Insulin-like growth factors and their binding proteins. Physiol Rev 70(3): 591-614, 1990. PMID: 1694588. DOI: 10.1152/physrev.1990.70.3.591

Received July 26, 2020

Revised September 15, 2020

Accepted September 16, 2020 